\title{
The new challenges of machining Ceramic Matrix Composites (CMCs): review of surface integrity
}

\author{
Oriol Gavalda Diaz ${ }^{a}$, Gonzalo Garcia Lunaa ${ }^{a}$ Zhirong Liao, ${ }^{a}$ Dragos Axinte ${ }^{a, b, *}$ \\ ${ }^{a}$ Faculty of Engineering, University of Nottingham, UK \\ b Faculty of Science and Engineering, University of Nottingham, Ningbo, China.
}

\begin{abstract}
Ceramic Matrix Composites (CMCs) are currently an increasing material choice for several high value and safety-critical components, fact that has recently originated the need of understanding the effect of several machining processes. Due to the complex nature of CMCs - i.e. heterogeneous structure, anisotropic thermal and mechanical behaviour and generally the hard nature of at least one of the constituents (e.g. fibre or matrix) machining become extremely challenging as the process can yield high mechanical and thermal loads. Furthermore, the orthotropic, brittle and heterogeneous nature of CMCs result in different material removal mechanisms which lead to unique surface defects. Hence, this review paper attempts to provide an informative literature survey of the research done in the field of conventional and non-conventional machining of CMCs with a main focus on critically evaluate how different machining techniques affect the machined surfaces. This is achieved by exploring and recollecting the different material characterisation techniques currently used to observe and quantify the mechanical and thermal surface and subsurface damages and highlight their governing removal mechanisms.
\end{abstract}

\section{Contents}

1. Introduction

2. Material definition

2.1. Surface integrity

2.2. Importance of the surface integrity for in-service performance

3. Conventional machining

3.1. Orthogonal cutting and scratch tests

3.2. Drilling

3.3. Milling

3.4. Grinding

4. Non-conventional machining

4.1. Pulsed Laser Ablation (PLA)

4.2. Abrasive Waterjet (AWJ) Machining

4.3. Electrical Discharge Machining (EDM)

5. Conclusions

6. Prospective outlook 


\section{Introduction}

Composite structures have got the attention of several industrial applications due to the possibility of improving the strength-to-weight ratio when compared to non-reinforced materials. Depending on the material forming the matrix, composites are commonly classified in PMCs (Polymer Matrix Composites), MMCs (Metal Matrix Composites) and CMCs (Ceramic Matrix Composites) [1]. Figure 1 shows these three main composite groups stating their most common reinforcement architecture (i.e. particulate or fibre reinforcements) and the materials often employed.

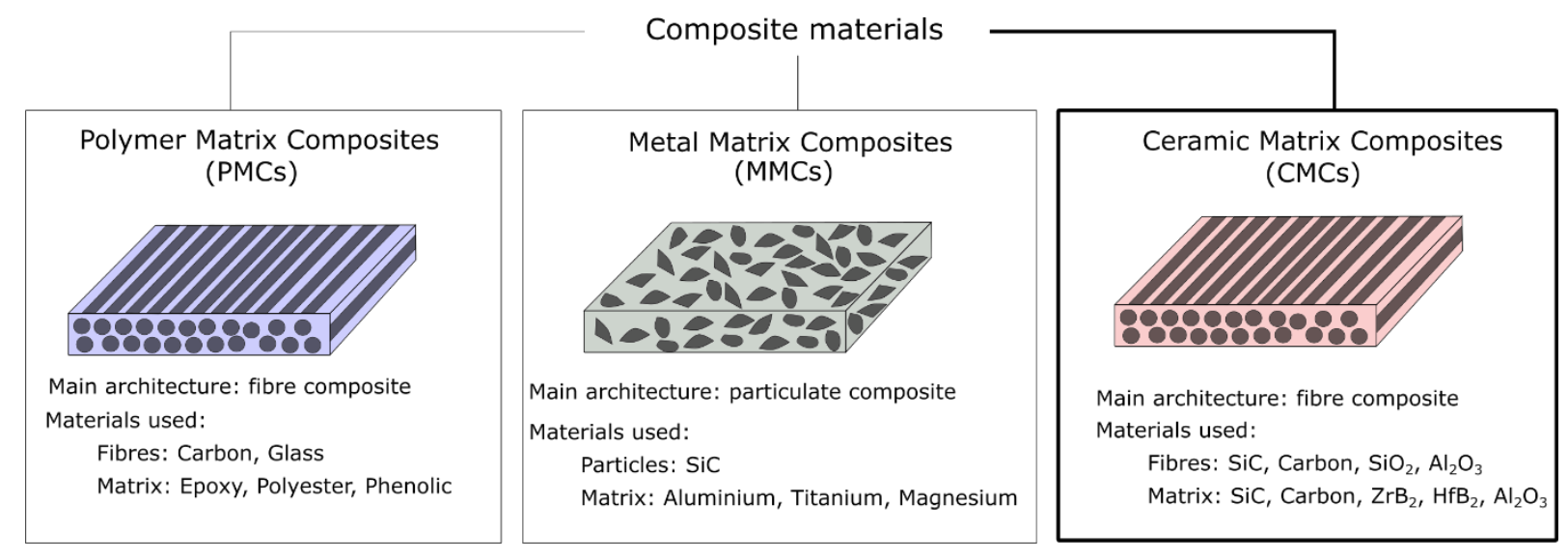

Figure 1 Classification of the composite materials depending on the nature of the matrix showing for each of them the main reinforcing architectures and materials used.

Concerning the field of machining composites, a large amount of research has been depleted and recollected in several reviews [2]-[4]. Nevertheless, these surveys only reported on the machinability of PMCs and MMCs. In the specific field of reinforced ceramics, a review was written focusing on the manufacturability and machining of particulate ceramics [5]. Therefore, as the field of long fibre reinforced CMCs has not been in-depth studied and because of the recent growth in demand of these material for high temperature structural applications (e.g. aerospace, automotive and nuclear industries [6]-[8]) it is believed that reporting about the current understanding in machining CMCs is of major scientific relevance. Furthermore, the effect that different machining processes induce to the surface integrity and the corresponding evaluations techniques needed to characterise these damages are not discussed either in the aforementioned reviews. Hence, as the machined surface is definitely a crucial aspect in structural components such as the ones that CMCs are be designed for, this review aims at collecting and critically analysing the different results achieved so far in the literature in reference to the surface integrity.

CMCs are considered challenging to be machined due to their unique nature. Hence, with the aim of providing a physical explanation of why they are considered the most difficult to machine composites, the main material-related properties affecting the machining process have explained and compared in a graph:

- Hardness $\left(\mathrm{H}_{\mathrm{v}}\right)$ : It can be related to the local resistance that a tool finds to indent or deform a material. Consequently, hard materials produce elevated mechanical and thermal cutting loads which result in a detrimental effect to the machined surface. In CMCs, considerably harder materials (compared to other composites such as PMCs or MMCs) are commonly used as a reinforcement (e.g. SiC fibres, $\mathrm{Al}_{2} \mathrm{O}_{3}$ ) and matrix (e.g. $\mathrm{SiC}, \mathrm{Al}_{2} \mathrm{O}_{3}$ ), as represented in the blue axis in Figure 2 . 
- Fracture toughness ( $K_{i c}$ : Represents the amount of energy needed to fracture a material. Hence, lower values of fractures toughness will be characteristic of materials tending to suffer a brittle removal mechanism. However, to compare the significance of these values in a cutting scenario among different materials, the hardness (as an indicator of the machining forces presented by the material) and fracture toughness (as an indicator of the tendency of the material of being removed in a brittle manner) should be used together. Hence, the green axis in Figure 2 represents the ratio $\mathrm{H}_{\mathrm{v}} / \mathrm{K}_{\text {ic }}$ for which large values translate to a greater tendency of occurring brittle fracture during cutting.

Therefore, it can be observed in Figure 2 that composites containing $\mathrm{SiC}$ and $\mathrm{Al}_{2} \mathrm{O}_{3}$ (closely followed by the silica glass) should be considered the most difficult to machine materials as they will yield higher cutting forces (caused by higher hardness) and will be more prone to suffer brittle fracture during the cutting process (caused by higher values of $\mathrm{H}_{\mathrm{v}} / \mathrm{K}_{\mathrm{ic}}$ ratio).

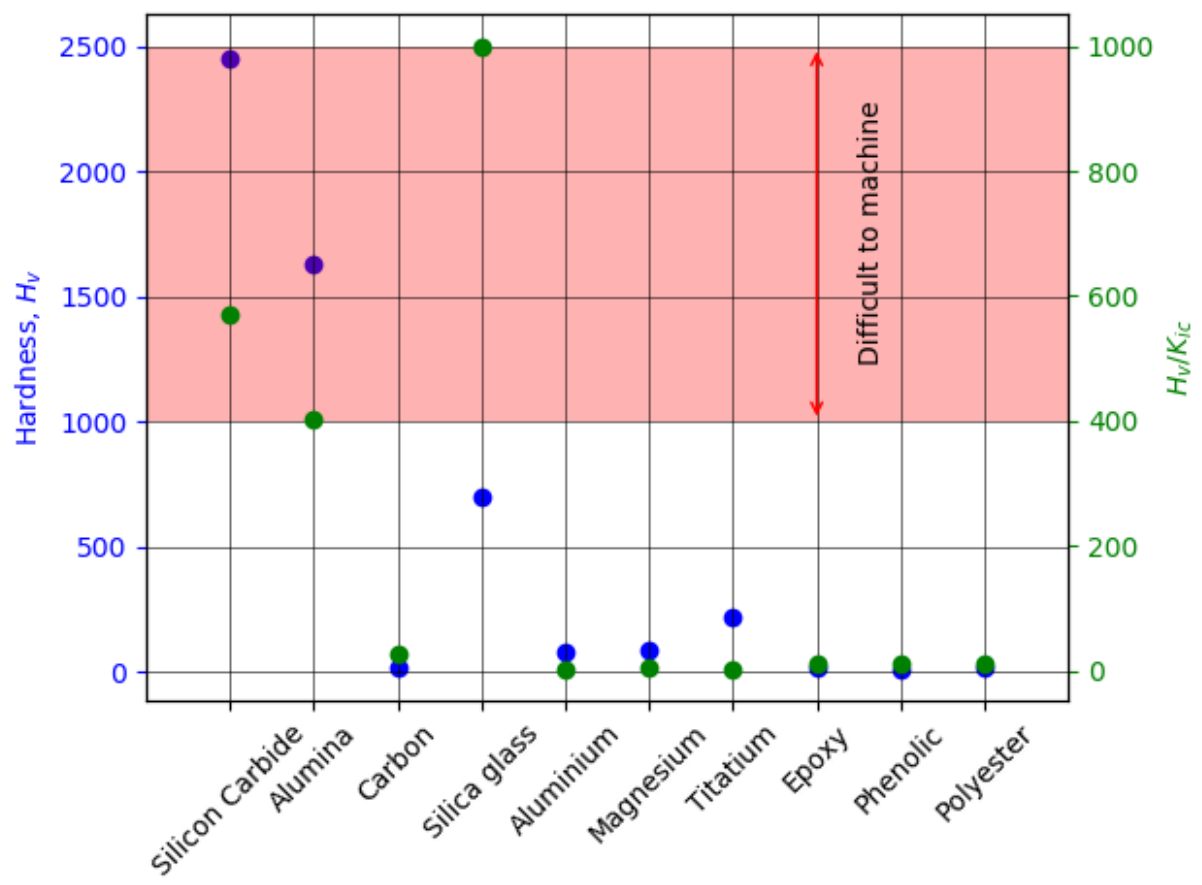

Figure 2 Approximate values from [9] of (a) $H_{v}$ (in blue) and (b) $H_{v} / K_{i c}$ (in green) for the different materials used in the manufacturing of composite structures such as PMCs, MMCs or CMCs (red band defining "difficult to machine" has been arbitrarily drawn just to highlight the materials with higher values).

Hence, it can be concluded that among all the composites, CMCs containing SiC and/or $\mathrm{Al}_{2} \mathrm{O}_{3}$ will display the highest machining forces and might tend to suffer a brittle removal mechanism. This combination is critical for the surface generation, especially when considering aerospace and nuclear applications, where small cracks can lead to a catastrophic failure. Hence, due to the challenges that these materials present for machining, in this review not only mechanical and conventional machining processes will be considered but also non-conventional ones such as laser ablation, abrasive waterjet and electrical discharge machining. 


\section{Material definition}

Engineered monolithic ceramics have been the material choice for several applications (e.g. mirrors in space telescopes, furnaces) due to their high hardness, stiffness and chemical resistance at high temperatures. Nevertheless, their brittle nature (especially the low fracture toughness) has prevented their implementation in critical structural applications. As ceramics composites reinforced with long fibres (CMCs) are designed with engineered interfaces between the fibres and the matrix, a controlled bridging mechanism of the cracks is achieved, resulting in an improved fracture toughness and hence, more promising mechanical properties [10] for structural applications such as in aero-engines or nuclear reactors. Figure 3 shows a summary table including the main types of CMCs (based on their matrix material) together with some examples of industrial applications.
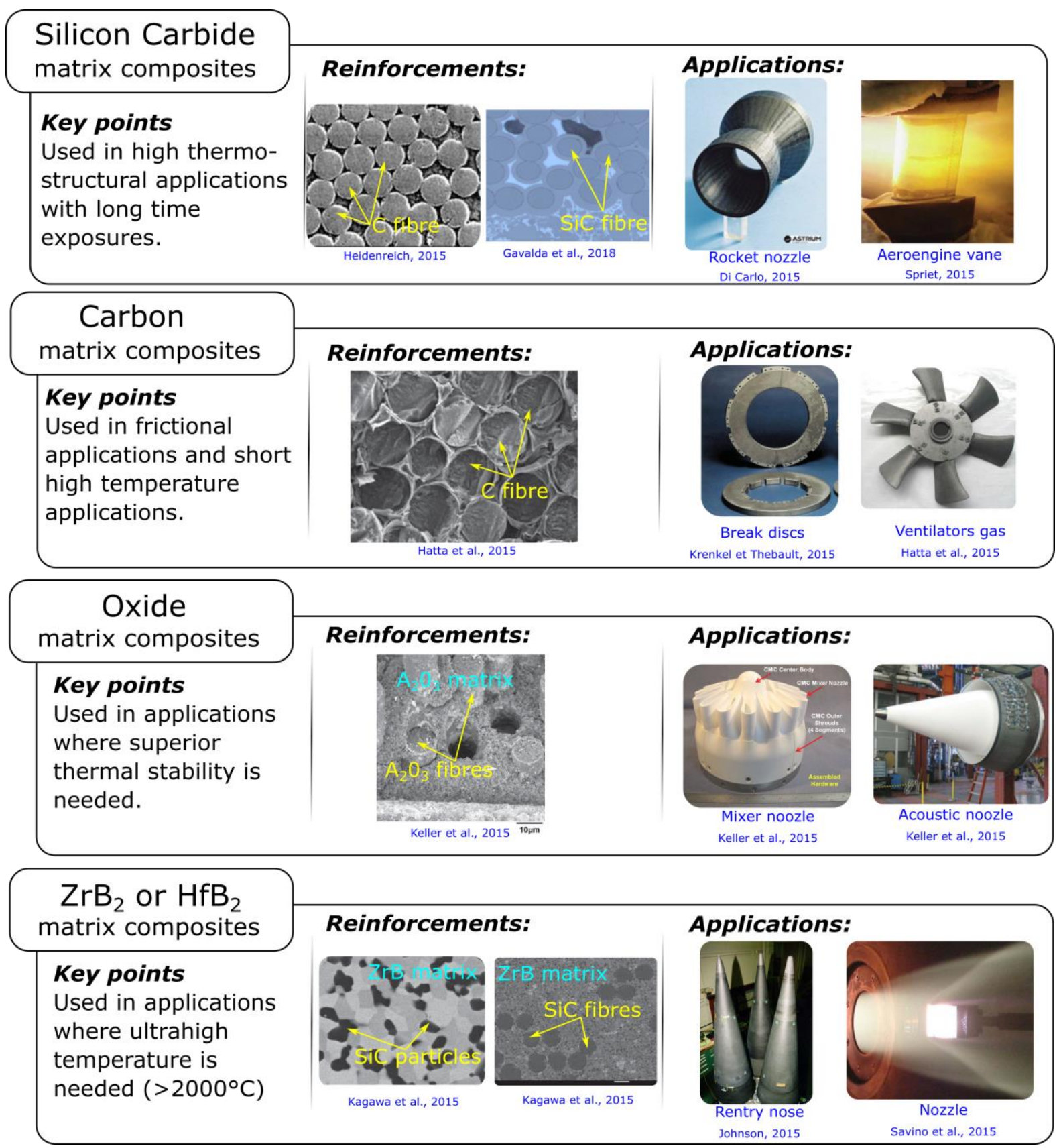

Figure 3 Summary of the main CMCs matrices with typical reinforcements and the most popular industrial applications [6], [7], [11]-[17]. 
$\mathrm{CMCs}$ are classified depending on the nature of the ceramic matrix: oxide (e.g. $\mathrm{Al}_{2} \mathrm{O}_{3}, \mathrm{SiO}_{2}$ or $2 \mathrm{Al}_{2} \mathrm{O}_{3} \mathrm{SiO}_{2}$ ) or non-oxide (e.g. $\mathrm{SiC}, \mathrm{C}, \mathrm{BN}, \mathrm{ZrB}_{2}$ or $\mathrm{HfB}_{2}$ ). Non-oxide CMCs are currently the most used materials due to their mechanical robustness at high temperature, especially SiC-based CMCs which is a trendy material choice for extreme applications such as aero-engines [18]. The most common non-oxide CMCs are $\mathrm{SiC} / \mathrm{SiC}, \mathrm{C} / \mathrm{SiC}, \mathrm{C} / \mathrm{C}$ or $\mathrm{SiC} / \mathrm{ZrB}_{2}$ and are treated in this review. Oxide-oxide CMCs are used due to their improved oxidation and degradation resistance in combustion environments [19] and are also covered in this review even if little amount of literature is available at the moment.

For both types of CMCs, similar ceramic phases (e.g. $\mathrm{SiC} / \mathrm{SiC}$ or $\mathrm{Al}_{2} \mathrm{O}_{3} / \mathrm{Al}_{2} \mathrm{O}_{3}$ ) are commonly used in the same structure in order to reduce the amount of residual stresses that can be generated during the manufacturing process. Several authors have studied how the processing temperature and the Coefficient of Thermal Expansion (CTE) mismatch affects the residual stresses between fibres and matrix by using Raman Spectroscopy, XRD or micro-hardness tests $[9,10,11]$. Depending on this CTE mismatch and the processing temperature, high levels of tensile or compressive residuals stresses were found in the CMC structures, condition that could affect or be affected by the machining process. Moreover, for the majority of CMCs, machining is challenging due to their very unique nature characterised by:

- High hardness

- Brittle or semi-brittle behaviour

- Orthotropic mechanical and thermal behaviour

- Highly heterogeneous structure (fibres, matrix and porosities)

\subsection{Surface integrity}

Surface integrity in a machining context is a measure of the effect that a material removal process has on the surface of a component, characterising the material-related changes (i.e. damages) that are formed [23]. Surface integrity has been an important research field when machining high performance metals such as Nickel and Titanium based alloys [24]. In general, three main aspects are studied when analysing the surface integrity:

- Surface topography: includes the characterisation of surface morphology such as roughness and waviness. In general, average values for the entire surface (e.g. average roughness, $\mathrm{Ra}$ ) are used for quantitative comparisons as direct relationship with the fatigue performance have been reported in the literature.

- Surface metallurgy: includes the metallurgic alterations of the surface and subsurface. In general, electron microscope techniques (i.e. SEM and TEM) coupled with Electron Bark Scattered Diffraction (EBSD) and X-ray Diffraction (XRD) are used to observe the crystal structure after machining and quantify the strains induced to the subsurface. In hard metallic alloys, a machining-induced recrystallization layer is formed in these materials and its thickness is commonly used as a quality control parameter.

- Mechanical characteristics: changes in hardness and residual stresses due to the machining induced deformation are quantified generally by micro indentation and XRD respectively. Commonly, a profile in depth of these two properties is provided to understand the subsurface mechanical alterations.

Nevertheless, due to the different and unique nature of CMCs, the material removal mechanism is completely different to metallic materials and consequently its surface 
integrity. Moreover, the fact of dealing with heterogeneous ceramic materials with smaller grain sizes, amorphous components and several interfaces, obliges to explore new methods of characterisation, as the conventional ones (i.e. XRD) might not be appropriate for measurements such as residual stresses. For this reason, this review paper focuses on reporting the surface integrity presented by CMCs when machining with conventional (i.e. drilling, milling or grinding) and non-conventional (i.e. pulsed laser, abrasive waterjet or electrical discharge) machining processes, stating the main characterisation routes while understanding the phenomenon that governs the material removal mechanism.

\subsection{Importance of the surface integrity for in-service performance}

CMCs are designed to resist harsh conditions such as cyclic mechanical and thermal loads in severe applications (e.g. in aerospace, nuclear or frictional). Hence, the surface and subsurface damages created during the machining processes need to be characterised in order to evaluate the component's life. Furthermore, the hierarchical structure of nonoxide CMCs (especially SiC-based CMCs) is designed to also resist in degrading environments (e.g. $\mathrm{O}_{2}, \mathrm{H}_{2} \mathrm{O}$ vapour, hydrocarbon or impurities such as $\mathrm{Na}^{+}$) [25]. Nevertheless, if its protecting surface layers fail, the internal structure can suffer an accelerated degradation leading to a brittle and catastrophic failure of the component [26]. Hence, a careful understanding of the effect of the machining process into the surface of CMCs is of critical relevance for the industrial community.

\section{Conventional machining}

Since CMCs are commonly used for complex parts (i.e. aero-engine vanes), conventional machining is the common process used to reshape the material and reach the geometry or assembly requirements. In this section, the different machining processes which are based on a conventional mechanical material removal with a tool are discussed. First, the fundamentals are presented by looking at the work done in orthogonal cutting and scratch tests. Afterwards, the processes of drilling, milling and grinding are explained in separate sections.

\subsection{Orthogonal cutting and scratch tests to enable the understanding material removal in machining of CMCs}

Orthogonal cutting and scratch tests are commonly used as a simplified scenario with the aim of capturing the basic phenomena in the material removal process occurring in machining. Orthogonal cutting is commonly assimilated to machining processes with defined cutting edges (e.g. drilling, milling), while scratch tests tend to be studied for the understanding of the effect of a single particle in an abrasive-based cutting processes (e.g. grinding).

Due to the orthotropic and brittle nature of long fibre reinforced composites, the orthogonal cutting on a $\mathrm{C} / \mathrm{C}$ material was studied for three different orientations: parallel, across and transverse; with the aim of understanding the different cutting and fracture mechanisms [27]. Figure 4 shows several frames of the high-speed imaging system obtained with the aim of understanding the different cutting mechanism that orthotropic and brittle materials, such as CMCs, can present. The material damage that appears for large uncut chip thickness and led by an unstable crack formation, was found to follow the fibre-matrix interface as it is the direction with a lower fracture toughness (see Figure 4 $d-f$ ). Nevertheless, for small uncut chip thickness (see Figure $4 a-c$ ), the translaminar 
fracture toughness for transverse fibres and the inelastic shear behaviour for parallel fibres were found to be the dominating factor in the cutting mechanism.
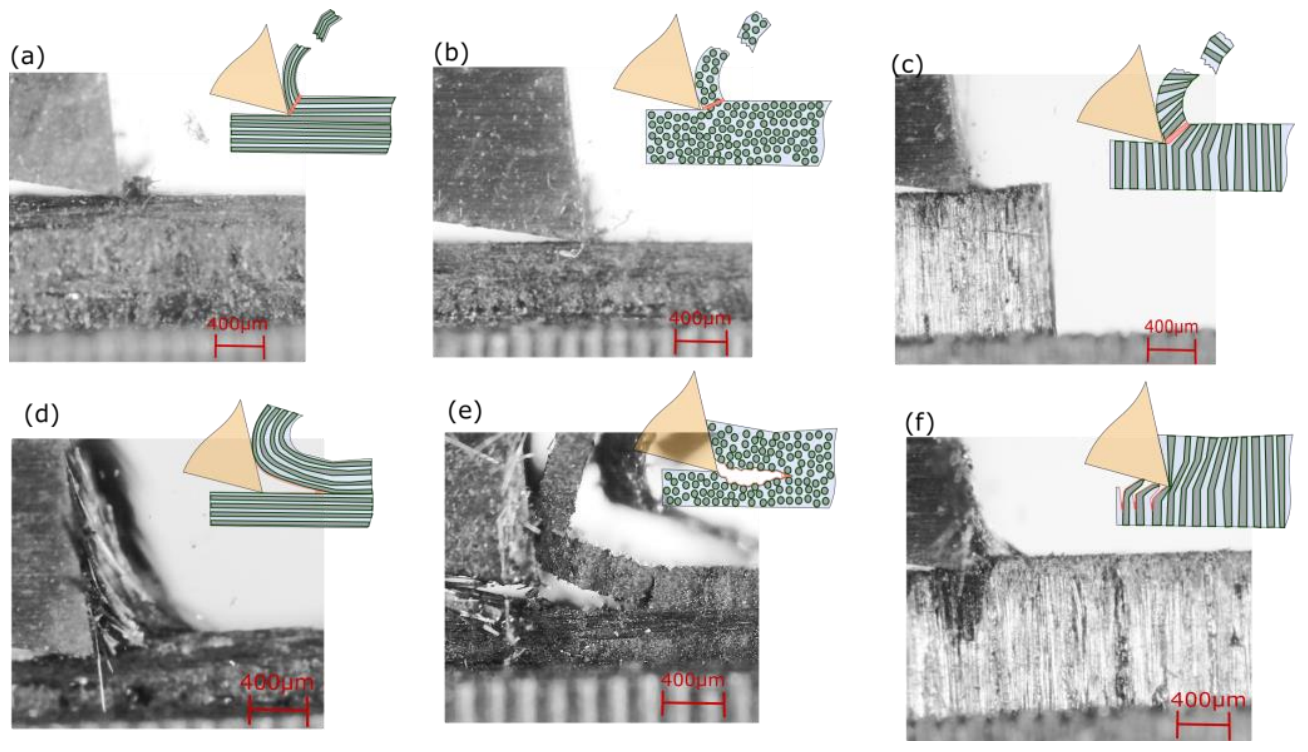

Figure 4 Frames of a high speed imaging system when performing orthogonal cutting in a C/C with three different fibre orientations (parallel, across and transverse) for a small uncut chip thickness (a), (b), (c) and for a large uncut chip thickness (d), (e), (f) respectively [27].

Liu et al. [28] performed dry grinding and scratch tests at different fibre orientations $\left(0^{\circ}\right.$, $30^{\circ}, 45^{\circ}$ and $90^{\circ}$ ) which showed that the scratched surface for $30^{\circ}$ and $45^{\circ}$ was more severely damaged than for $0^{\circ}$. In the case of fibres oriented at $30^{\circ}, 45^{\circ}$ and $90^{\circ}$, the fibres were not completely removed due to the large bending deformation during the movement of the grid. This results in a severe lateral damage as shown in Figure 5.

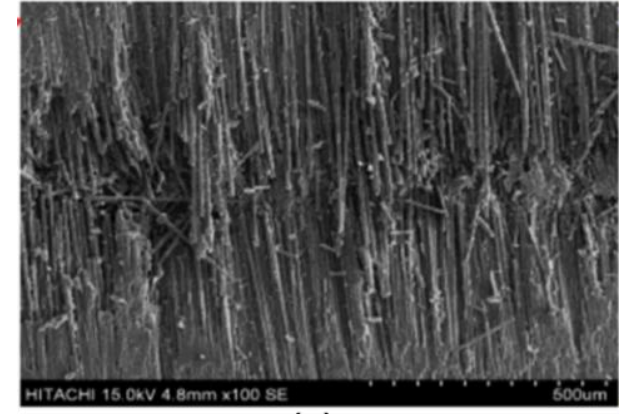

(a)

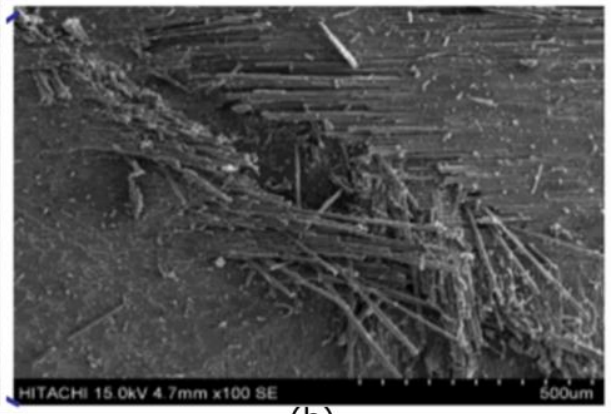

(b)

Figure 5 SEM images of a C/SiC with a scratch angle of (a) $90^{\circ}$ and (b) $45^{\circ}$ showing the bending mechanism of the fibres and the induced lateral damage [28].

Even if the reinforcement of CMCs is mainly based on long fibres, the study of the effect of ceramic matrices reinforced with ceramic particles is of high relevance as some Ultra High Temperature CMCs are particle reinforced (as mentioned in Figure 3). Moreover, in some long fibres CMCs, the matrix itself can be a particulate ceramic, as it is the case of some melt infiltrated SiC/SiC. Ghosh et al. $[13,14]$ studied the behaviour of a particulate $\mathrm{ZrB}_{2}-\mathrm{SiC}$ when performing scratch tests at different loads. Even if the main objective of the study was not to understand the material removal mechanism but to comprehend the impact resistance, similarities in the results can be obtained as very small uncut chip thickness are normally used when machining hard ceramics/CMCs. It was reported that 
microcracking and microplasticity were dominating the scratch behaviour leading to the conclusion that both, ductile and brittle phenomena might appear when machining ceramics at small uncut chip thickness. Overall, the particulate nature led to a pull out (i.e. debonding) or grain fracture mechanisms in the SiC-particle regions and slip planes in the $\mathrm{ZrB}_{2}$ areas (Figure 6).
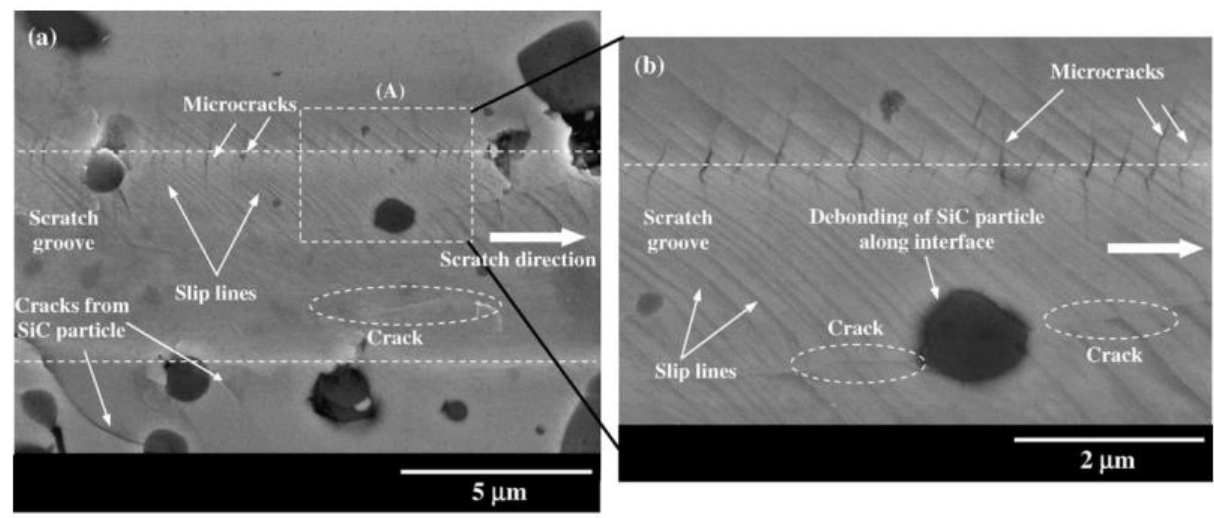

Figure 6 (a) SEM images of the scratch induced deformation in a ZrB ${ }_{2}$-SiC for a load of $250 \mathrm{mN}$ showing (b) slip-line patterns and micro cracks along the scratch groove [29].

Furthermore, the roughness of the machined surface was shown to be highly dependent on microcracking mechanisms of the particles and concluding how important the reinforcement is in the surface topography obtained after machining composite materials. The effect in the residual stresses was evaluated in the same material by using micro Raman Spectroscopy in the SiC particles [31], showing an increase of tensile residual stress when rising the scratch load. However, as $\mathrm{ZrB}_{2}$ is not Raman active, the residual stress evolution in the matrix, which represents a $95 \%$ of the material, were not quantified.

\subsection{Drilling}

It can be learnt from the orthogonal cutting work that, when using machining operations for which the tool rotates along its axis (i.e. drilling or milling), a combination of the different cutting mechanisms appears (as schematically represented in Figure 7), and resulting in different effects in the surface integrity. Consequently, it is important to emphasise that average or generic values of surface topography, microstructure or mechanical characteristics might not be representative when characterising the machined surface in orthotropic materials such as CMCs.
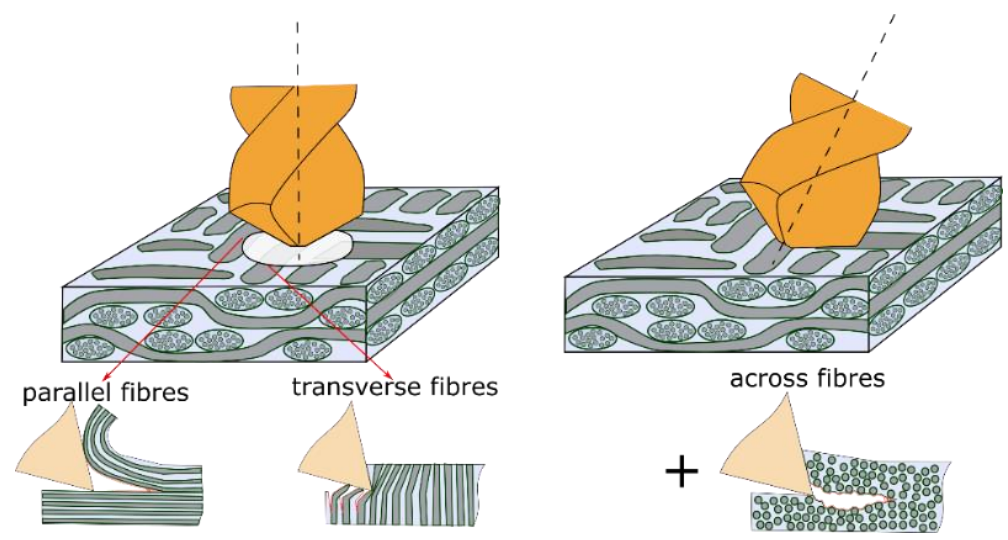

Figure 7 Influence of the fibre orientation when drilling perpendicular and tilted holes in orthotropic material such as CMCs. 
The hole-making processes research in CMCs has mainly focused on the comparison between conventional drilling (CD) and rotary ultrasonic machining (RUM) using abrasive tools; this is not surprising research avenue since conventional (e.g. carbide, diamond coated) drills wear rapidly in hard structures like CMCs. The main CMC material studied has been the $\mathrm{C} / \mathrm{SiC}$ for which relative high thrust forces appear due to the hard nature of the SiC matrix and the challenging surface finish that, due to the brittle nature of the Carbon fibres, is difficult to achieve. Because of the high thrust forces together with the laminated nature of CMCs, entry and exit delaminations are a machining induced damages that have been widely investigated. Figure $8 \mathrm{a}$ and Figure $8 \mathrm{~b}$ show the three mechanisms that form the exit delamination (i.e. tearing, burring and edge chipping) and the influence that this damages have depending on the fibre orientation [32], [33]. Several authors [34]-[37] concluded that Rotary Ultrasonic Machining (RUM) produced an overall lower thrust force $(\approx 10-15 \%[34])$ which was translated to a less significant exit delamination.
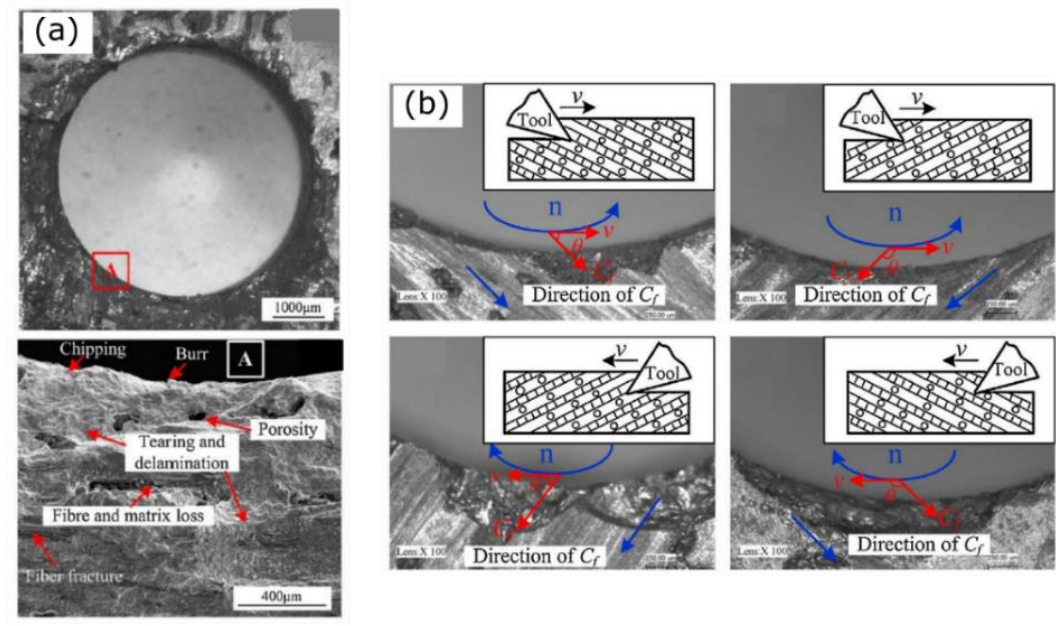

Figure 8 Exit delamination in CMCS showing (a) SEM image an exit delamination in a $\mathrm{C} / \mathrm{SiC}$ material showing three different regions: tearing, edge chipping and burring (b) the influence of the fibre orientation in the delamination [33].

Nevertheless, even if exit delamination is a relative important factor, it can be highly improved by three main approaches:

- Adding a back-up or supporting plate (for example made in graphite which is a rigid material that holds the sample but at the same time can be easily cut), as proposed in [33].

- Designing improved drill geometries that produce a lower thrust force, an example is proposed in [32].

- Using more gentle cutting parameters (in general lower feed rates) although these might not be applicable in industry.

Consequently, in this review, the surface integrity (e.g. fracture morphology, residual stresses...) of the hole walls is considered a more compelling and challenging factor that needs further characterisation and study. Due to the orthotropic nature of long-fibre reinforced CMCs and the rotation direction of a drill bit, different fibre orientations are found during the cutting process, significantly affecting the machined surface [27], [38]. Wang et al. [38] studied the influence of the process (RUM against conventional drilling) with no obvious evidence that the later improved the surface finish. Figure 9 shows the different surfaces obtained for RUM and conventional drilling for the four different fibre orientations $\left(0^{\circ}, 45^{\circ}, 90^{\circ}\right.$ and $\left.135^{\circ}\right)$. 


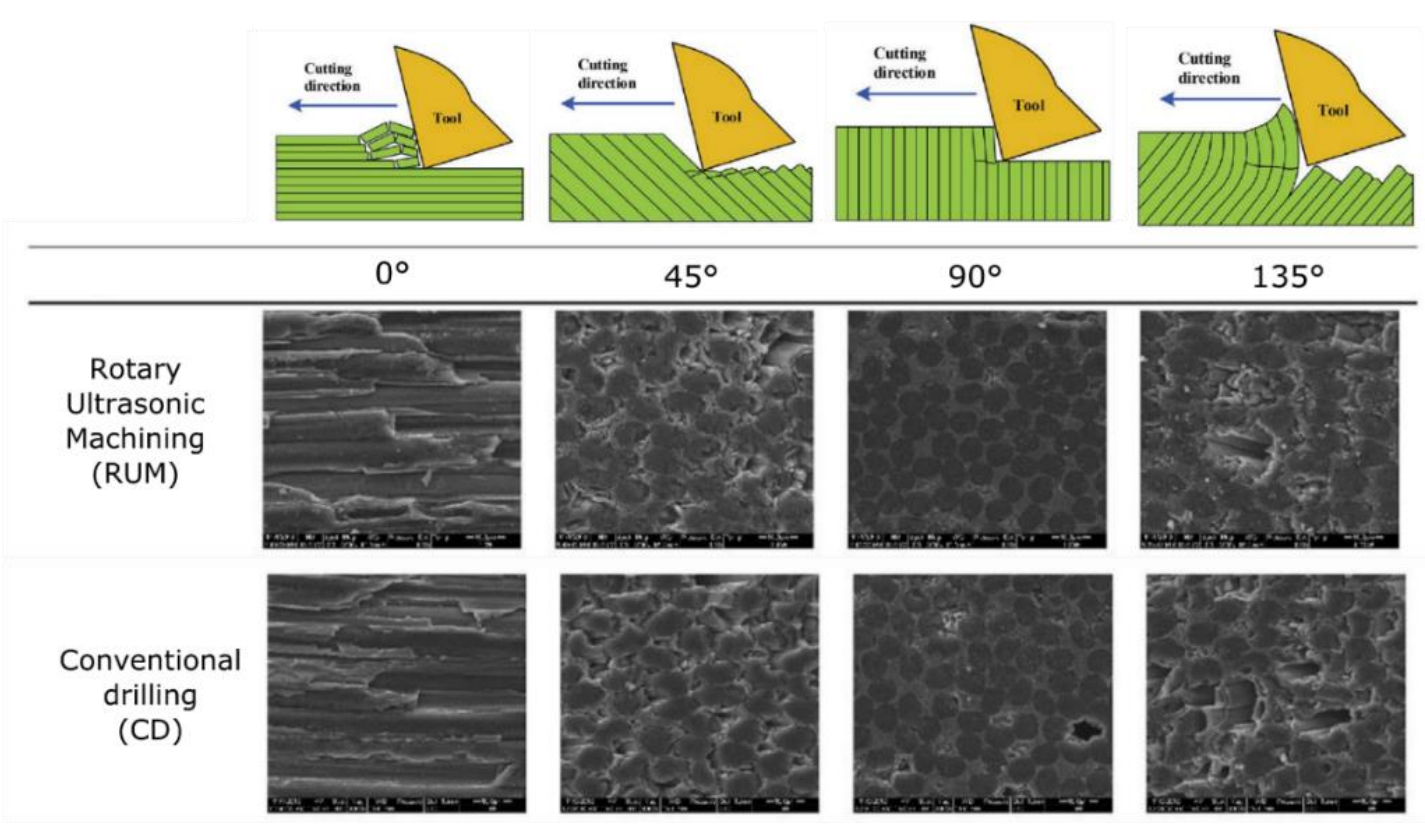

Figure 9 Surface integrity considering different fibres orientations $\left(0^{\circ}, 45^{\circ}, 90^{\circ}\right.$ and $135^{\circ}$ ) for Rotary Ultrasonic Machining (RUM) and Conventional Drilling (CD) [38].

A more in-depth analysis of the morphology and microstructure of the machined surface was carried out in a $\mathrm{SiC} / \mathrm{SiC}$ when drilling with a standard diamond coated drill [39]. It was reported that, different components of the CMC structure - i.e. fibres (Hi-Nicalon $\mathrm{SiC}$ ), fibres' coatings (Chemical Vapor Infiltration CVI-SiC), particles in the matrix - displayed various deformation and fracture mechanisms even if their common SiC-based nature, as shown in Figure 10. The understanding of the material removal mechanism was then evaluated by characterising the surface integrity and showing a fracture dominated behaviour in the fibre-rich region and a more ductile mechanism in the matrix-rich region.

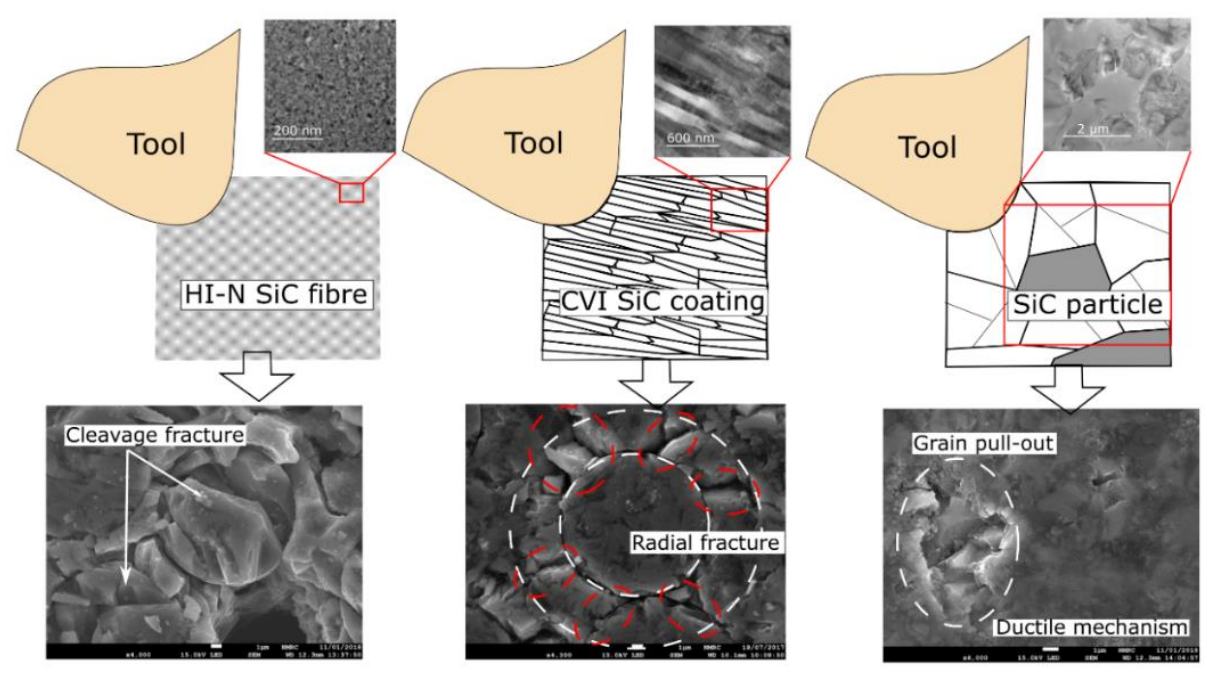

Figure 10 Material removal mechanism and surface integrity for the different constituents of a SiC/SiC structure: Hi-Nicalon (Hi-N) SiC fibres, Chemical Vapor Infiltrated (CVI) SiC coating and SiC-Si matrix [39]. 
This was further studied by characterising the residual stresses via micro Raman spectroscopy that the CMC structure presented after the material removal process. Due to the different Raman spectra that each element of the CMC structure has (i.e. fibres, Si and $\mathrm{SiC}$ ), it was possible to measure the residual stresses for each component after a specific fitting routine. This resulted in tensile residual stresses in the fibres and compressive in the matrix [39].

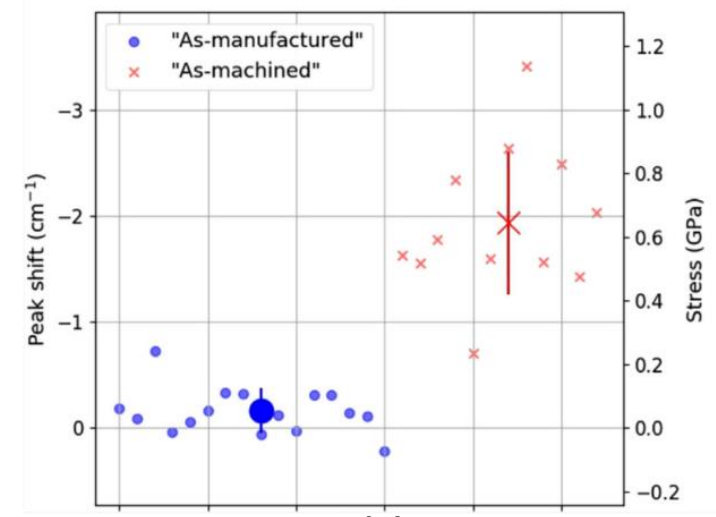

(a)

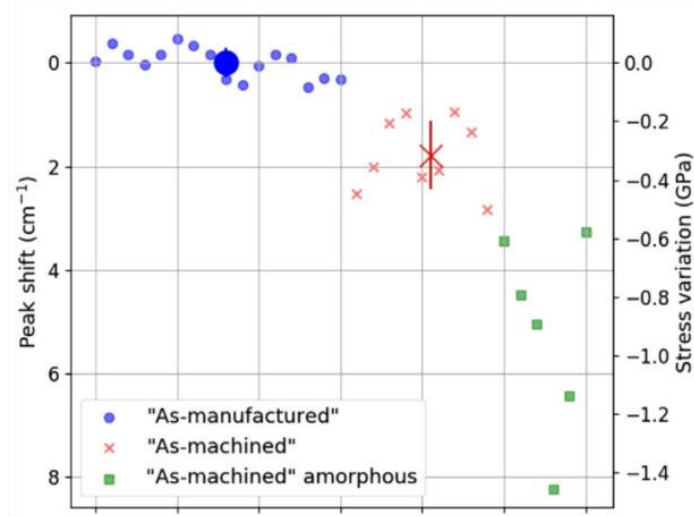

(b)

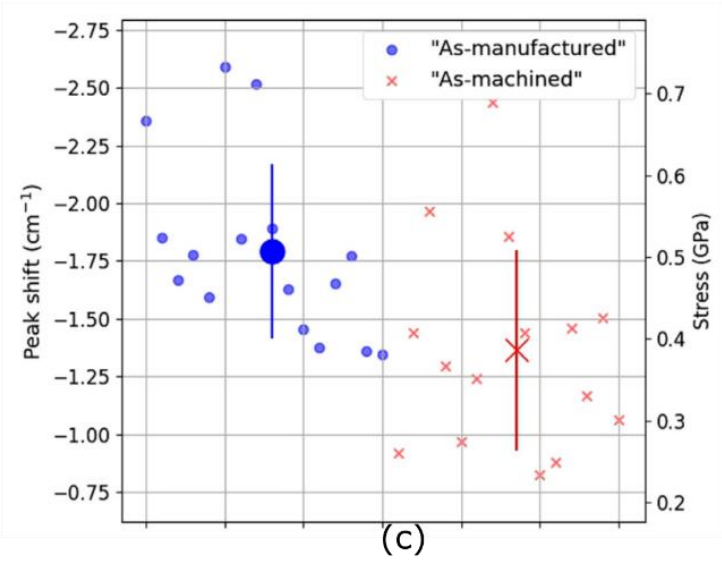

Figure 11 Residual stresses before ("as-manufactured") and after ("as-machined") the machining process obtained via Raman spectroscopy in the (a) Hi-Nicalon SiC fibres, (b) free Si found in the matrix and (c) SiC particles forming the matrix [39].

Gavalda Diaz et al. [40] also studied how the hard-heterogeneous nature of SiC-based CMCs affects the drilling performance when machining small holes (between 0,8 and 5 $\mathrm{mm}$ diameter) with standard twist drills. It was reported that, because of this unique nature of SiC-based CMCs, premature tool brakeage happens when machining with small tool diameters (i.e. $0,8 \mathrm{~mm}$ diameter). This was analytically and experimentally explained based on a radial force measured during the drilling trials, not appearing when machining other hard materials such as monolithic SiC. It can be observed from the schematic in Figure 12 how, due to the heterogeneous distribution of tows, matrix and porosities, the drill bit is surrounded at each instant by different constituents, leading to an instability effect of the drilling process. 


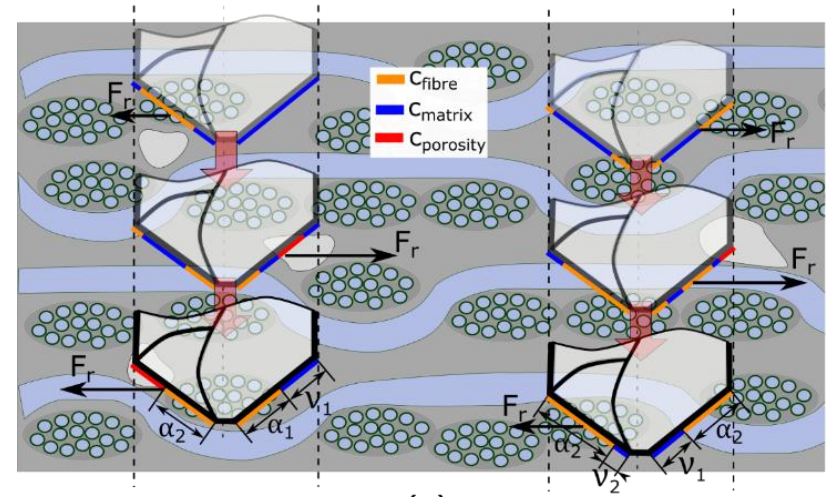

(a)

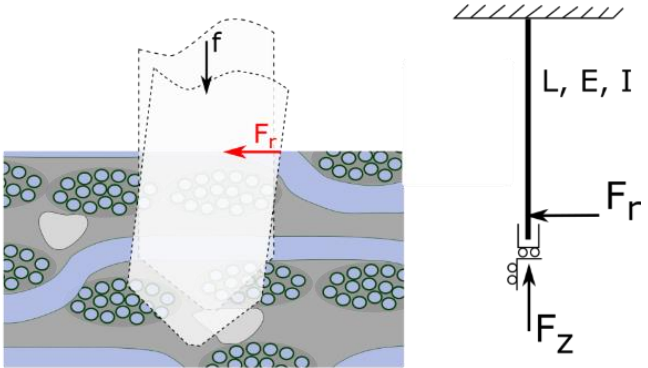

(b)

Figure 12 (a) Schematic showing how the distribution of fibres, matrix and porosities can affect induce a radial force and (b) force diagram showing the radial instability that the drill suffers when machining hard CMCs [40].

\subsection{Milling}

Similarly to what has been reported in drilling, most of the studies in milling of CMCs have been focused on the comparison between conventional and ultrasonic assisted milling. Few researchers worked on force prediction models [41], [42], while others evaluated the surface finish by looking at the roughness and the morphology of the machined surface [43]. Yuan el at. [44] identified the critical penetration depth which induces a ductile-tobrittle transition in rotatory ultrasonic face milling (RUFM) of C/SiC. It was concluded that, for penetration depths greater than $4 \mu \mathrm{m}$, the surface roughness suddenly increased, presenting larger number of grooves and craters (due to a brittle fracture). On the other hand, for smaller values of penetration depth, the Carbon fibres tended to be more continuous without large fractured areas. Similar conclusions were drawn when milling $\mathrm{C} / \mathrm{C}$ composites, where a slightly improved surface finish was obtained with ultrasonic instead of conventional milling. Evidence of a ductile-to-brittle transition during the machining was observed in the matrix, while a pull out mechanism was dominating the fibre removal mechanism [45].

The study undertaken by Bertsche et al. [46] compared the performance of conventional milling against rotatory ultrasonic machining (RUM) for making slots in SiC/SiC. It was demonstrated that, although the RUM workpiece had a more homogeneous surface roughness, it yielded overall greater values than the ones obtained via conventional milling (see Figure 13a and Figure 13b). In the study, no explanation on the causes were given but it could be assumed that the main reason relies on the dynamics of the RUM process that, due to the vibratory displacement of the tool, the SiC-based CMC is continuously impacted forming uncontrolled microcracks. This can then result in greater values of surface roughness than if carefully chosen parameters are used in conventional machining processes to achieve a semi-ductile material removal mechanism. The fundamental principle behind this is that during indentation (or impacting) of brittle materials, median and radial cracks tend to be formed, as shown in Figure $13 \mathrm{c}$ and previous reported in rotary ultrasonic machining of brittle materials [43]. 


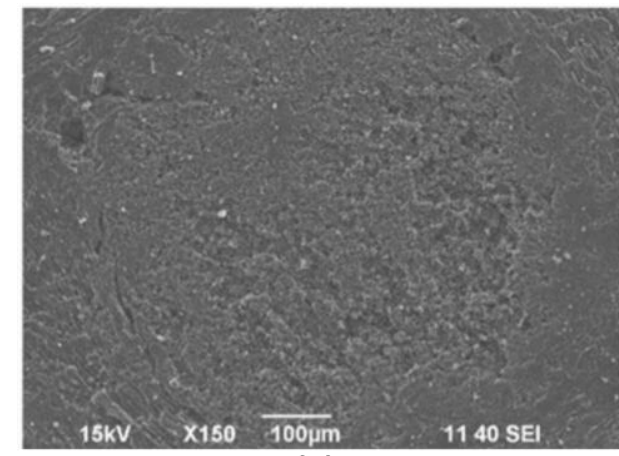

(a)

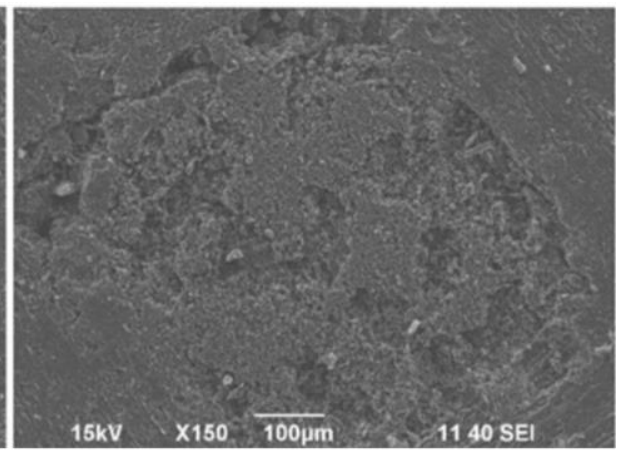

(b)

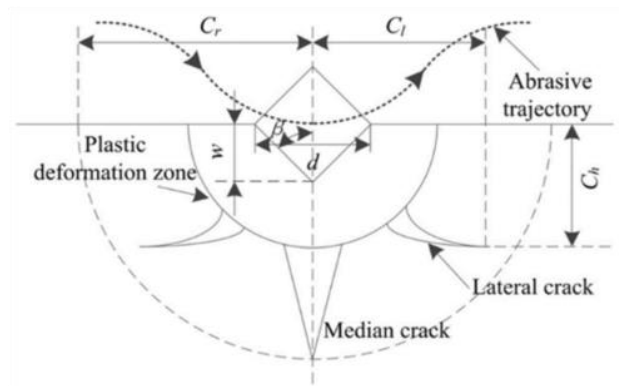

(c)

Figure 13 Surface comparison between (a) RUSM and (b) CG [45]. (c) Crack system (median and radial) in single-edge non-overlapping cut with cutting velocity directed normal to the plane of cross-section in a brittle material [43].

As an alternative method to reduce the process-induced forces and tool wear (which is a very significant issue when machining SiC-based CMCs) and further enhance the surface finish, investigations have been undertaken to analyse the feasibility of using laserassisted machining to soften the material ahead of the tool before cutting. Despite the technique has been shown to be cost-effective, reduce the cutting forces and the tool wear [47], [48]; little amount of work has been found in the literature in terms of in-depth characterisation of the surface integrity after milling of CMCs, so that the authors identify here an open ground for interesting research topic.

\subsection{Grinding}

Finishing operations are commonly needed for CMCs to achieve the close tolerances required in the aerospace and nuclear industries. Amongst all the abrasive machining processes, grinding is the preferred finishing operation for brittle and hard materials as it might be one of the few options to achieve high dimensional and geometrical part accuracies at acceptable material removal rates. Many studies focused on the observation of the material morphological characteristics, such as the fibre orientations and wave patterns, to explain the material removal mechanism and understand surface integrity resulting after grinding. A schematic of the grinding process for the longitudinal, transverse and across fibre orientations is illustrated in Figure 14 [49]. 


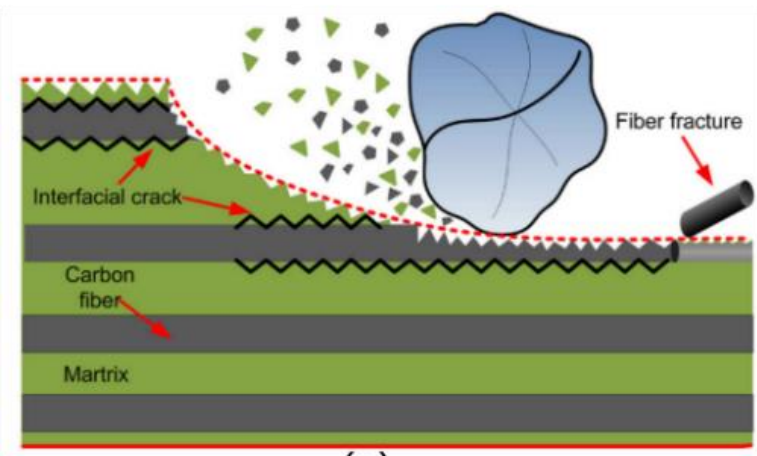

(a)

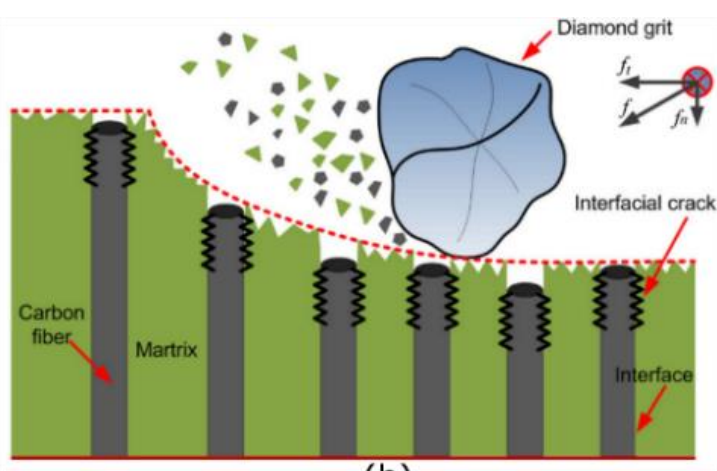

(b)

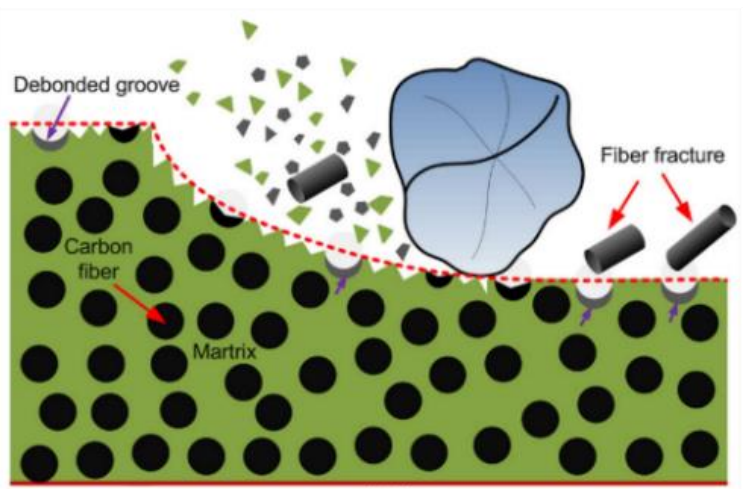

(c)

Figure 14 Schematic diagram of the different fibre orientation when grinding CMCs: (a) longitudinal fibres, (b) transverse fibres and (c) across fibres [49].

The grinding process in a $\mathrm{C} / \mathrm{SiC}$ has been studied by several authors. Zhang et al. [49] reported similar values of surface roughness for all the fibre orientations $\left(R_{a} \approx 1 \mu \mathrm{m}, \mathrm{R}_{\mathrm{z}} \approx\right.$ 5-10 $\mu \mathrm{m})$, but for the lower wheel speeds $(\approx 19.6 \mathrm{~m} / \mathrm{s})$ (i.e. higher uncut chip thickness) the surface roughness increased dramatically when grinding along the longitudinal direction ( $R_{a} \approx 6.5 \mu \mathrm{m}, \mathrm{R}_{z} \approx 45 \mu \mathrm{m}$ ). This could be caused due to a propagation of the cracks along the fibre interfaces which resulted in voids produced by the fibres being pulled-out. In contrast, at higher wheel speeds $(\approx 39.3 \mathrm{~m} / \mathrm{s})$ (i.e. lower uncut chip thickness) the material removal was accomplished in a brittle manner, mainly by a combination of fibre fracture and matrix cracking [49], [50]. The surface achieved for different orientations in a $\mathrm{C} / \mathrm{SiC}$ after a grinding process has been shown in Figure 15. 


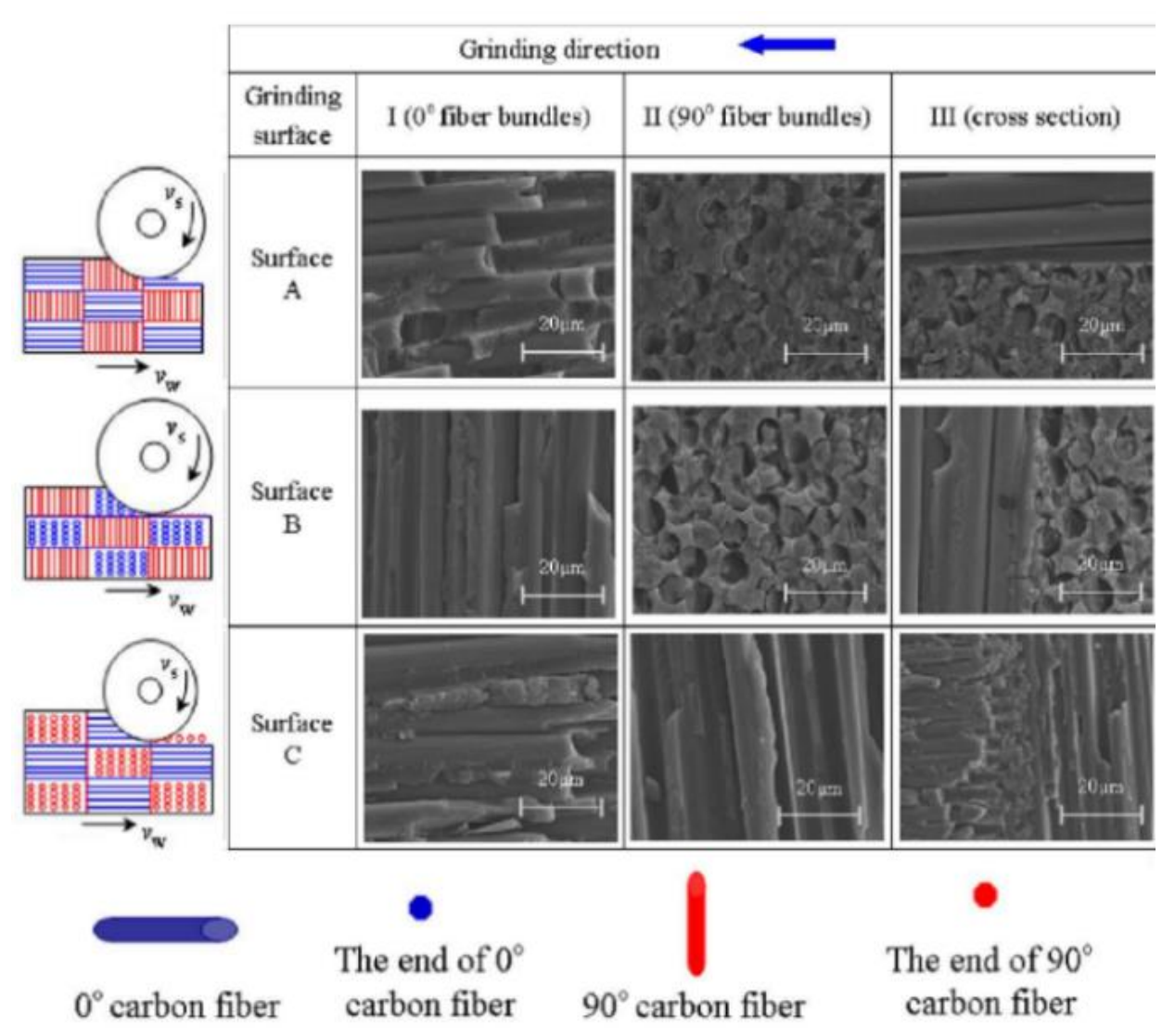

Figure 15 SEM micrographs of C/C-SiC in the different combinations of fibres orientation and schematic of the grinding direction on the workpiece surface [50].

Du et al. [51] tried to relate the grinding process parameters to the machined surface obtained along the different fibre orientations on a 2D C/SiC. Nevertheless, the surface roughness seemed not to have a direct trend with the uncut chip thickness, probably because of the complexity of the material removal process. Exfoliation of the Chemical Vapour Infiltration (CVI) SiC matrix found on top of the fibres was observed when grinding along the longitudinal direction of the fibres (Figure 16a). Both sheared and fractured fibres were reported under grinding conditions along the transverse direction, as can be seen on Figure 16c. Furthermore, when grinding across the fibres, some of them were found to be fractured parallel to their longitudinal axis (Figure 16b). 


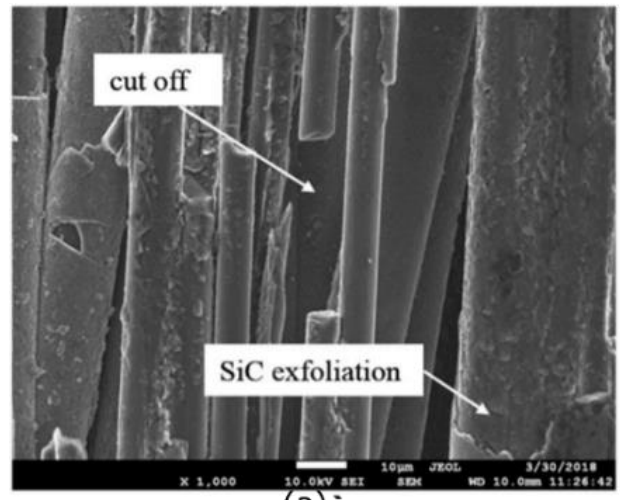

(a)

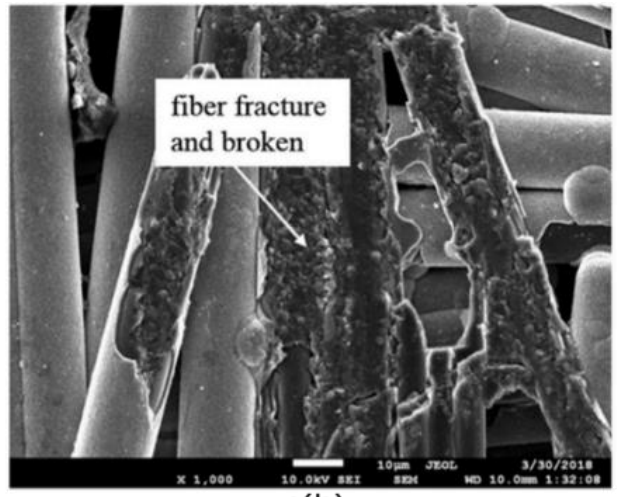

(b)

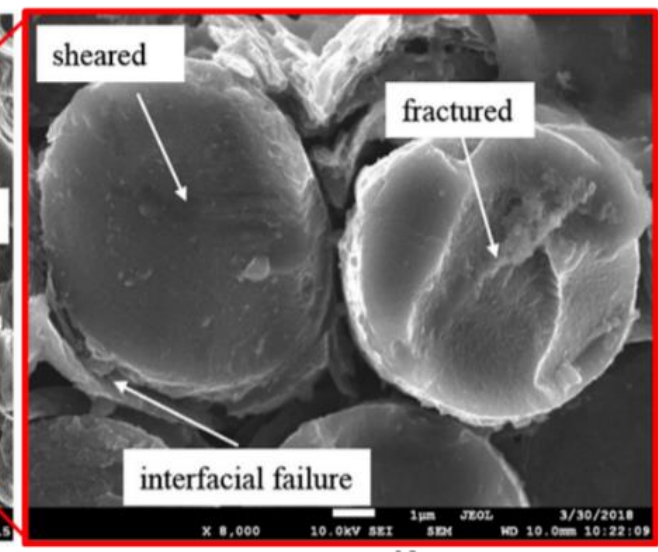

(c)

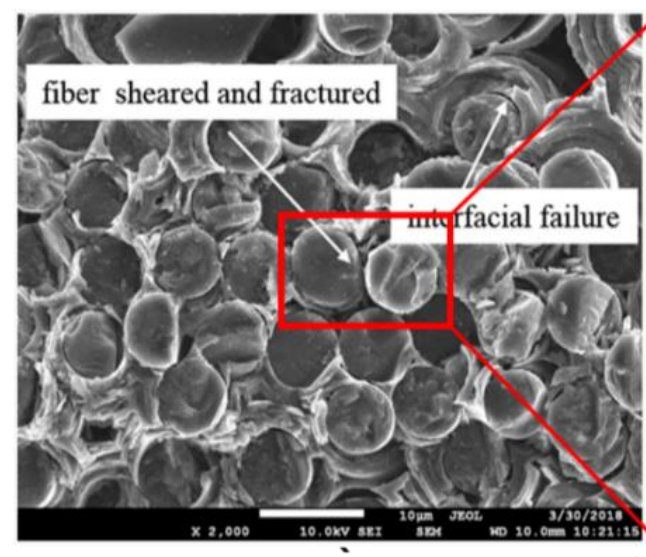

Figure 16 Ground surface morphology in (a) longitudinal, (b) across, (c) and (d) transverse directions of the fibre [51].

Furthermore, this study commented that for specific fibres, a so-called "extrusion fracture" was observed and characterised for an uneven lamellar fractured surface (see Figure 17a). It was explained that, this type of fracture resulted from a crack propagation in a nonperpendicular direction to the longitudinal axis due to the bending of the fibres. However, it could be added that this fracture phenomena could also be linked to the morphology of the fibre structure (in this case onion-skin like) if different types of structures (e.g. random, radial or mixed) were commonly found in the same Carbon fibre reinforced CMC. To endorse this hypothesis, further research was performed into whether pitch-based Carbon fibres can display different transverse textures depending on the spinning temperature at which the pitch is heated. In fact, there is a change of slope in the viscositytemperature diagram at a transition temperature below which either random or onion-skin structures can be obtained [52], Figure 17b. This leads to belief that the fracture surface shown in Figure 17a could be due to different fibre structures (i.e. random and onion-like) which are randomly formed during the melt spinning process of the Carbon pitch. 


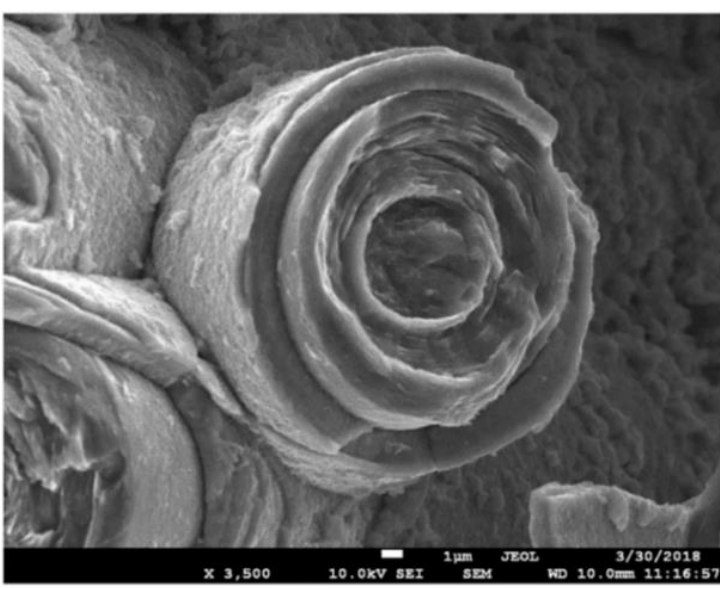

(a)

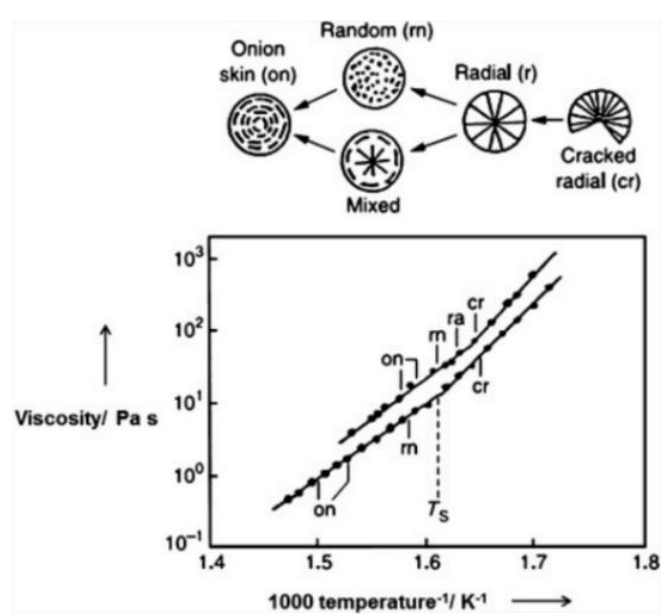

(b)

Figure 17 "Extrusion fracture" of a carbon fibre [51] probably due to its onion-skin structure and (b) different carbon fibre structures with varying melt spinning for two types of pitch [53].

Few investigations concerning oxide-oxide CMCs are reported in the literature with the most studied material being a 2.5D woven $\mathrm{SiO}_{2} / \mathrm{SiO}_{2}$ [54]-[56]. These articles focused on the surface roughness, waviness and morphology after the grinding process but no indepth studies have been reported in relation to the surface integrity, which in turn is one of the major challenges when machining CMCs and an essential aspect for the assessment of the grinding or any other machining process. From the investigation, the grinding process was reported to be based on crack propagation mechanisms along the fibre-matrix interface for $0^{\circ}$ fibres and matrix shearing and fibre fracture (with shorter crack propagation) along the interface for $90^{\circ}$ fibres [56].

Experimental studies conducted to compare different grinding strategies (i.e. conventional grinding (CG), ultrasonic assisted grinding (UAG) and intermittent grinding (IG)) were also found in literature. According to the experiments performed by Tawakoli and Azarhoushang [57] in two different C/SiC materials, CG yielded an improved surface roughness compared to IG ( $\approx 2-4$ times lower values of $R_{a}$ for $C G$ ). However, the residual stresses in the surface ground with the segmented tool (IG process) were lower, apparently due to a reduction in the rubbing stage of grinding and consequently the process temperature [58]. Nevertheless, in the aforementioned publication, the residual stresses were measured by analysing the X-ray diffraction patterns without previously specifying the methodology followed, which, in the authors opinion, is fundamental for a good interpretation of the results (due to the heterogeneous and pre-stressed nature of CMCs). On the other hand, UAG produced higher values of surface roughness than CG due to the continuous impact of the abrasive grains into the ceramic, which caused cracks to propagate [59]. The extent of the subsurface damage observed when grinding $90^{\circ}$ fibres with UAG was reported to be less significant than in CG (as shown in Figure 18). However, it is believed that the damage might not very regular along the surface and the parameters chosen might not have been optimised for CG, as the uncut chip thickness calculated for the experimental conditions reported in [59], [60] is considerably higher than the brittleto-ductile transition found for other similar CMCs. In addition, Ding et al. [61] demonstrated that the surface integrity can be improved in CG of CMCs if the process parameters are selected carefully. 


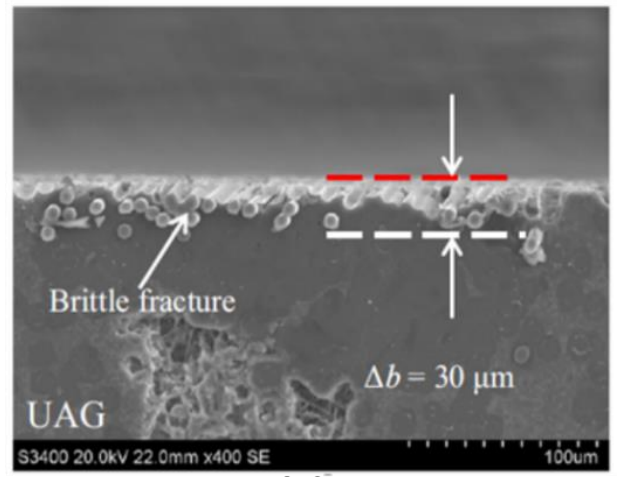

(a)

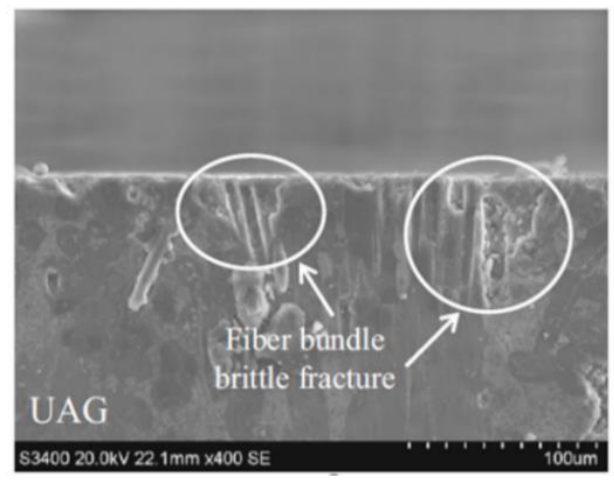

(c)

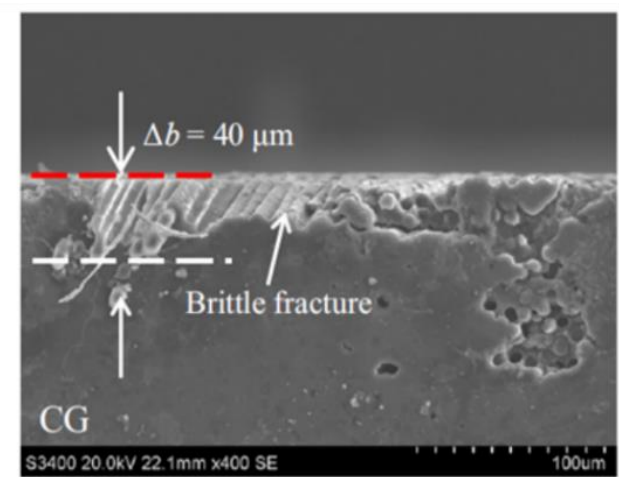

(b)

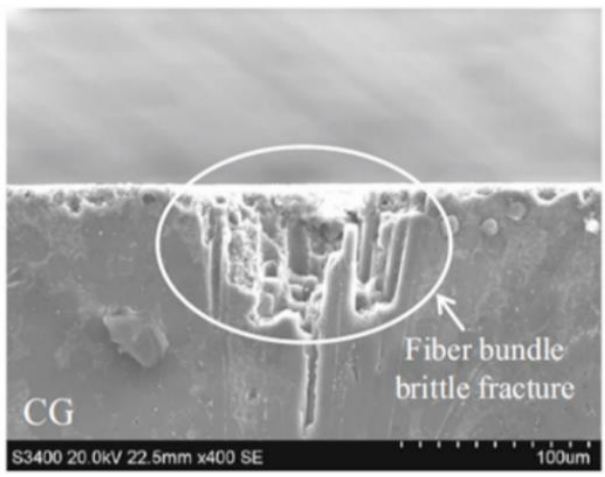

(d)

Figure 18 SEM images of subsurface damage in $90^{\circ}$ fibres produced by UAG and CG [60].

Hence, it can be concluded that the surface integrity in conventional machining of CMCs is mainly influenced by the different material removal mechanisms that different fibre orientations (e.g. parallel, transverse...) and materials (e.g. SiC fibres, SiC coatings, SiC particles...) within the same CMC structure display. Moreover, apart from the residual stress values presented in [39], it is difficult to obtain quantitative data which characterises the machined surface. This is because compare values of surface roughness might not have physical sense as they clearly depend on the fibre orientation and region being measured (i.e. fibre or matrix). On the other hand, it has been shown that features such as holes (larger than $1 \mathrm{~mm}$ diameter), slots and surface finishing can be successfully machined with conventional mechanical techniques by mainly using diamond and cubic boron nitride tools.

\section{Non-conventional machining}

\subsection{Pulsed Laser Ablation (PLA)}

Laser machining is a viable process to CMCs, especially for the hole-making in ultra-hard SiC-based CMCs as the conventional drilling of small holes can become challenging [62] due to the hard and heterogeneous nature of the CMCs. Moreover, compared to other glasses or ceramics, SiC species have shown to absorb the laser wavelength effectively, establishing the laser as a relatively efficient machining technique [63]. Concerning the surface integrity, one of the main drawbacks in laser ablation is the heat affected zone (HAZ). Hence, especial attention has been paid in terms of oxidation and degradation analysis of the non-oxide ceramics (i.e. SiC and $\mathrm{C}$ ) commonly found in $\mathrm{CMC}$ materials. It is well known in the literature that, in order to reduce the thermal damage, pulsed laser 
ablation is recommended, leading to different technologies such as millisecond, nanosecond, picosecond or femtosecond laser ablation, depending on the pulse duration.

The millisecond laser ablation was studied by looking at the influence of the processing parameters to the machined surface. Several pressure assisted gases (e.g. $\mathrm{N}_{2}, \mathrm{Ar}, \mathrm{O}_{2}$ ) were proved to give different results in terms of Silicon oxidation, observing evidently that an $\mathrm{O}_{2}$ atmosphere produced a greater silicate phase. However, this oxidation layer was not quantified nor characterised in-depth [63].

Laser ablation, with the aim of smoothing the surface, with a nanosecond laser was studied in a $\mathrm{SiC} / \mathrm{SiC}$ and a C/SiC CMCs structures. After the laser treatment, a decrease in the carbon content while an increase of the oxygen peak were observed from an EDS analysis, concluding that the $C$ phase tended to suffer a faster oxidation than the Si [64]. When decreasing the pulse duration, the influence of the debris-removal mechanism becomes more important, especially for long aspect ratio holes. This phenomena was studied for a picosecond laser ablation in $\mathrm{C} / \mathrm{SiC}$ and $\mathrm{SiC} / \mathrm{SiC}$ [62], [65] reporting that, when using low energy densities (e.g. $0.51 \mathrm{~J} / \mathrm{mm}^{2}$ ) the debris tended to not be removed, leaving an irregular surface finish and being unable to produce through-holes (Figure 19a). On the other hand, when the energy density was increased (i.e. $1.52 \mathrm{~J} / \mathrm{mm}^{2}$ ), through-holes were able to be machined even if some irregularities were still found, especially at the exit and on the hole wall (Figure 19).

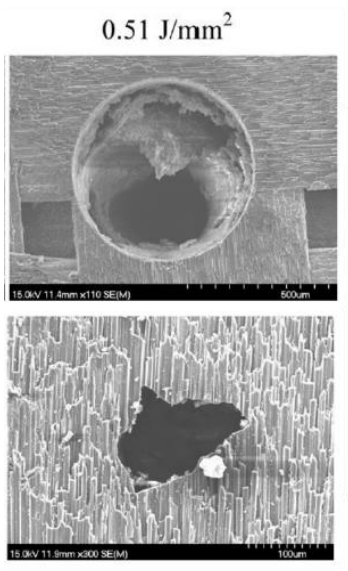

(a)

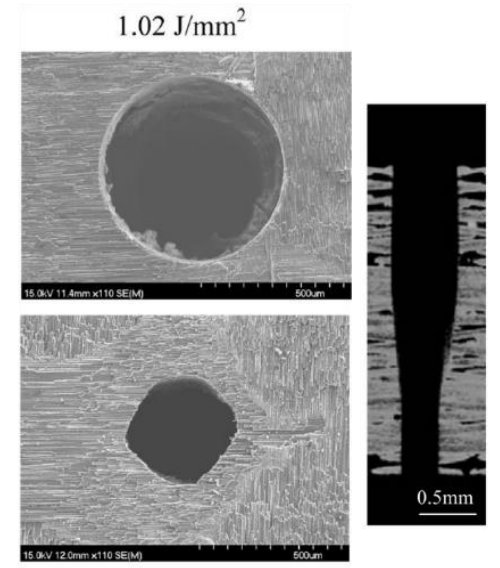

(b)

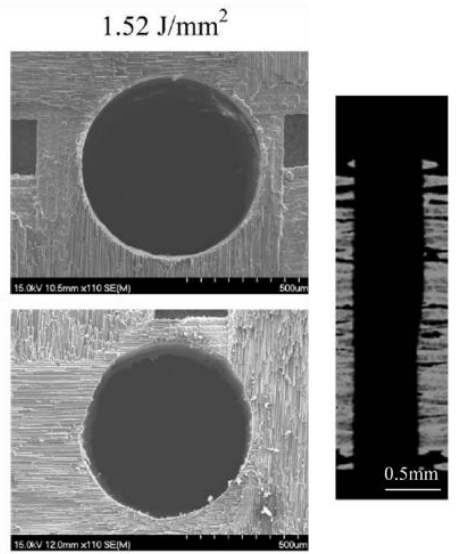

(c)

Figure 19 SEM images of the hole entry, hole exit and X-Ray CT of the hole geometry when laser-drilling a $3 \mathrm{~mm}$ thick C/SiC with a (a) $0.51 \mathrm{~J} / \mathrm{mm}^{2}$, (b) $1.02 \mathrm{~J} / \mathrm{mm}^{2}$ and (c) $1.52 \mathrm{~J} / \mathrm{mm}^{2}$ [65].

A more in depth analysis of the degradation found in non-oxide CMCs after laser ablation was performed by characterising the debris and machined surface in a C/SiC [65], [66] when using picosecond laser ablation. $A \approx 10 \mu \mathrm{m}$ layer induced by laser ablation was found at the entry (see Figure 20d and Figure 20e) and on the hole walls (see Figure 20b and Figure 20c), concluding via EDS its oxidised nature. A similar analysis was performed in a $\mathrm{SiC} / \mathrm{SiC}$ concluding that the most suitable laser power is a compromise between oxidation, which increases with the power, and hole-shape quality, which decreases with the power [43]. To reaffirm the formation of an oxide layer when machining SiC-based CMCs and obtain further information, a quantitative analysis was performed by measuring the atomic percentage of elements via X-Ray Photoelectron Spectroscopy (XPS). As shown in Figure 21 , the results clearly demonstrated an increase of the oxygen content in the machined surface when rising the laser power [62]. 

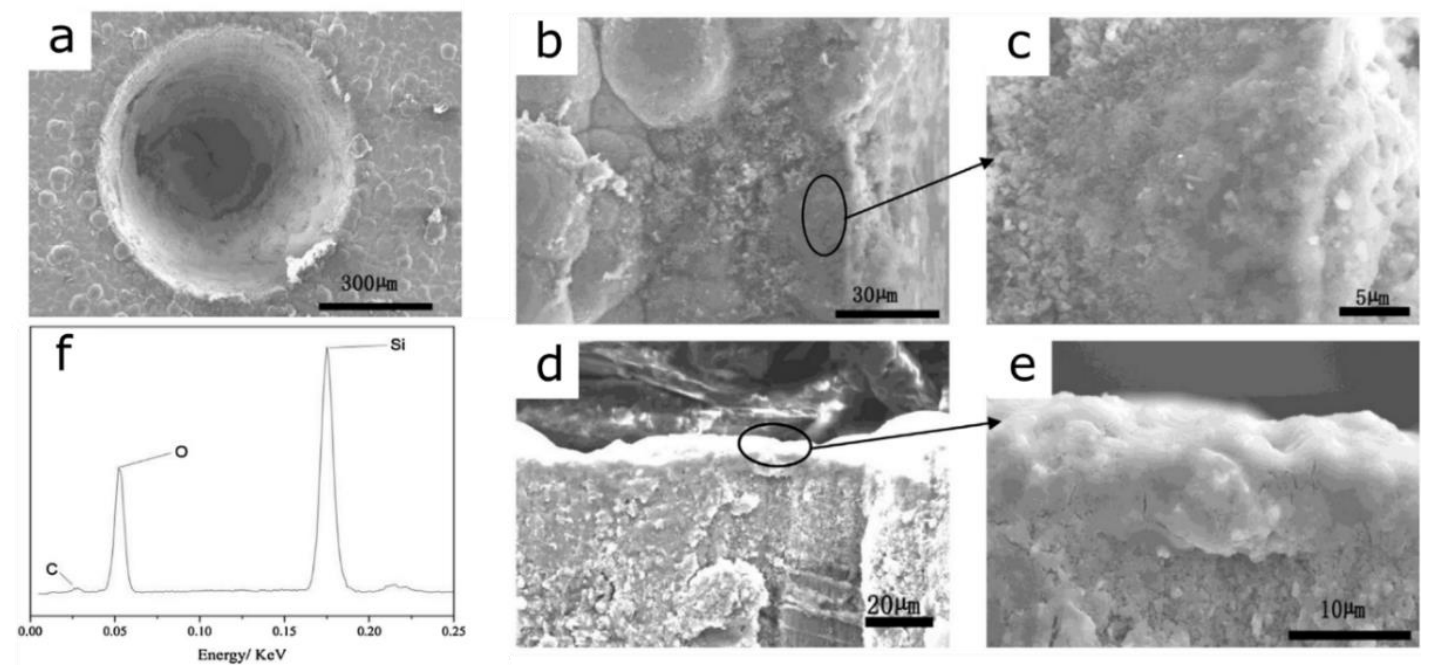

Figure 20 SEM analysis of a C/SiC sample showing (a) general view of the hole, (b) and (c) Silica formation in the cross section of the hole (d) and (e) Silica formation at the entry of the hole and (f) EDS spectra of the layer [66].

(a)
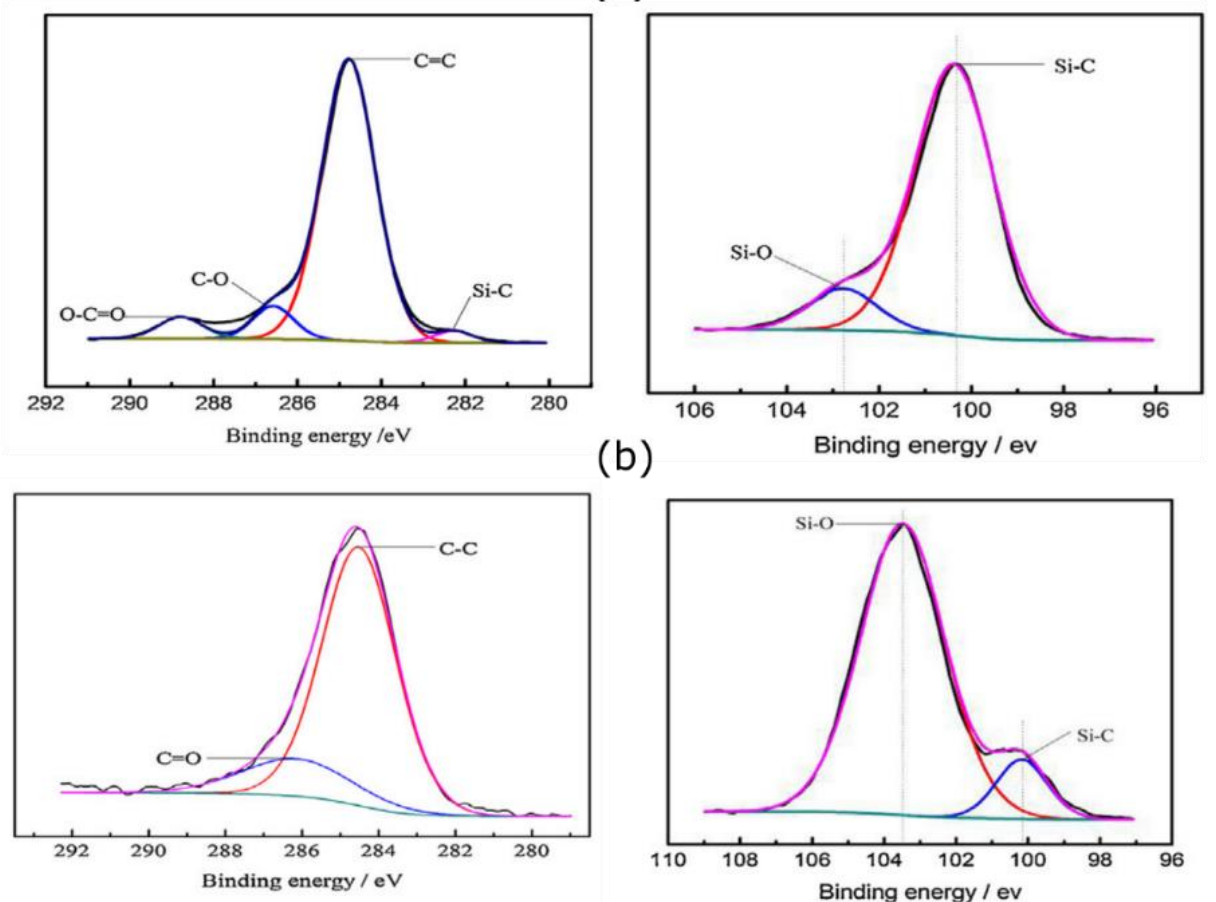

(c)

\begin{tabular}{rlll}
\hline Processing power $(w)$ & \multicolumn{4}{l}{ At \% of elements contained in debris } \\
\cline { 2 - 4 } & $\mathrm{C}$ & $\mathrm{Si}$ & $\mathrm{O}$ \\
\hline 0 & 58.19 & 28.35 & 13.46 \\
4 & 38.15 & 22.71 & 39.14 \\
6 & 30.04 & 21.44 & 48.52 \\
8 & 18.36 & 20.86 & 60.78 \\
10 & 24.78 & 12.93 & 62.29 \\
12 & 19.35 & 16.29 & 64.36 \\
\hline
\end{tabular}

Figure 21 Surface analysis of a SiC/SiC machined with a picosecond laser showing (a) XPS spectra of the material as-received, (b) XPS spectra of the material as-machined and (c) table showing a the XPS quantitative analysis for different processing powers 
Femtosecond laser ablation was used to machine holes in C/SiC [67], [68], SiC/SiC [69], [70] and $\mathrm{SiC}-\mathrm{TiC}-\mathrm{TiB}_{2}$ [71]. This research found that even with femtosecond ablation technologies, the $\mathrm{SiC}$ species tended to produce a silica-based oxide in the ablated surface [70]. However, compared to nanosecond ablation, the femtosecond technology produced a considerably reduced amount of silica (in this specific case between 4 and 5 times less) [71]. In Zhai et al. [68] work, the influence of the surface convexities that CMCs have due to their heterogeneous nature and complex manufacturing process was studied giving interesting results on how the machined profile is affected. It is concluded that the convexities fount in the irregular surface and the heterogeneous nature of CMCs resulted in uncontrolled abnormalities in the shape of the machined tranches (see Figure 22).

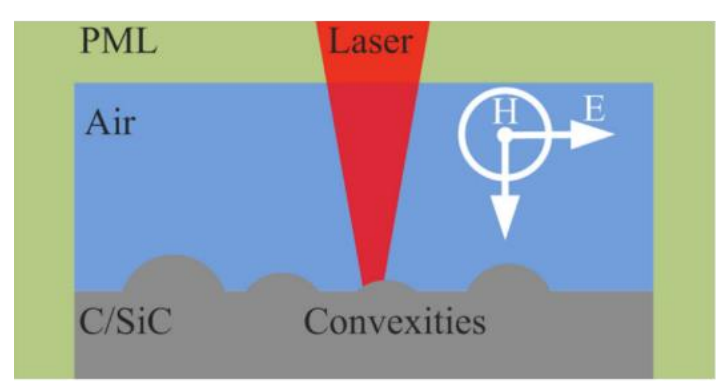

(a)

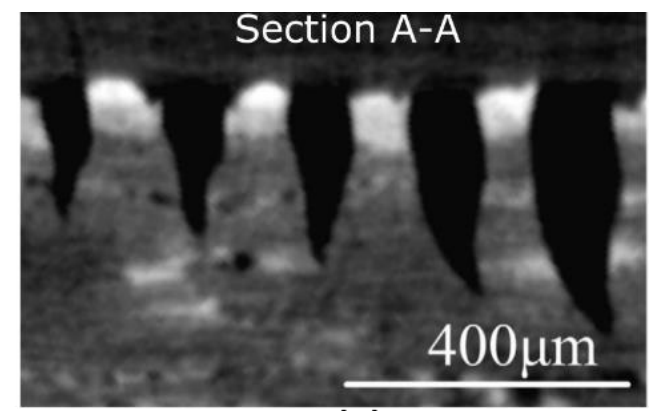

(c)

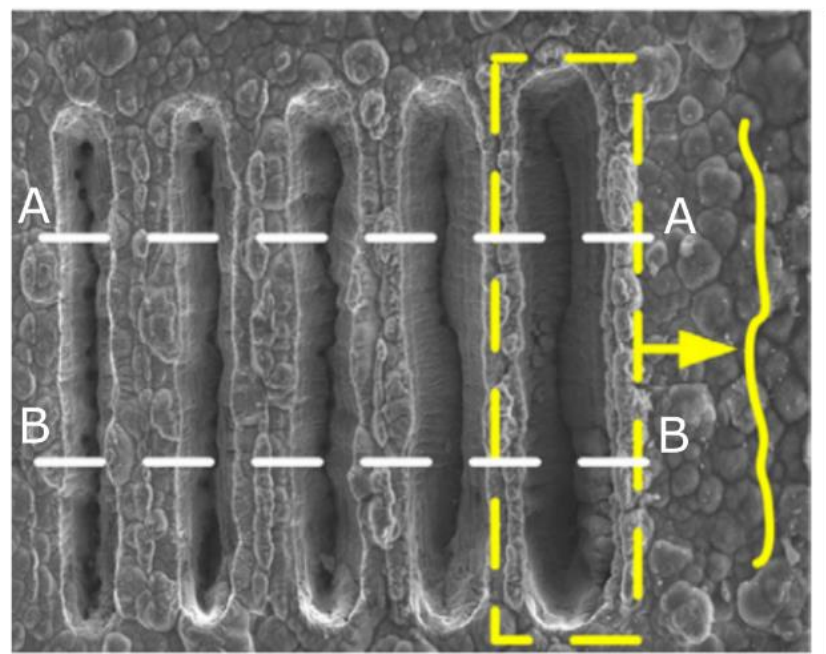

(b)

Figure 22 (a) Schematic showing how the convexities influence the laser beam incidence (b) trenches obtained in a C/SiC for $1 \mathrm{~W}, 100 \mu \mathrm{m}$ defocus at different speeds and (c) Micro CT scan showing the Section A-A in (b) [68].

Hence, it can be concluded that PLA can be an interesting technique to machine small features (i.e. holes or slots) and to smooth surfaces in CMC structures. However, one of the big drawbacks when machining with pulsed laser ablation is that the machining time can be long [66] and therefore, it might not be a suitable technique for large features such as holes with either larger diameters or long depths (e.g. holes with a larger diameter than 1-2 $\mathrm{mm}$ and depth of 4-5 mm). Moreover, it is well known from the literature that the oxidation of non-oxide CMCs can affect the life performance of the component and therefore, the influence of the laser in the mechanical performance of CMCs should be further studied. 


\subsection{Abrasive Waterjet (AWJ) machining}

Abrasive Water Jet (AWJ) machining has been shown to be a promising process to cut and shape hard ceramics such as SiC [72] and reinforced materials [73], [74].

A feasibility study on a particulate reinforced ceramic $\mathrm{TiB}_{2} / \mathrm{SiC}$ was performed by looking at the hole-making and slotting operations, showing a favourable potential of the technique for hard ceramic composites [75]. However, a reduced surface quality was found at the jet exit due to the tapering effect (kerf tapper angle) and a more brittle/fracture removal mechanism due to the loss in energy of the jet (especially for thick samples).

In difficult-to-machine long fibre reinforced ceramics, the machining process becomes more challenging due to the orthotropic fracture properties that especially 2D woven CMCs present. As explained by Ramulu et al. [76], the high pump pressure (e.g. 400-600 MPa) is needed to perforate the material can be easily dissipated in the form of interlaminar cracking or ply delamination. For this reason, machining features where the jet is started within the sample (as represented in Figure 23a) might tend to be more challenging for $2 \mathrm{D}$ woven $\mathrm{CMC}$ structures than edge features, as represented in Figure $23 \mathrm{~b}$.
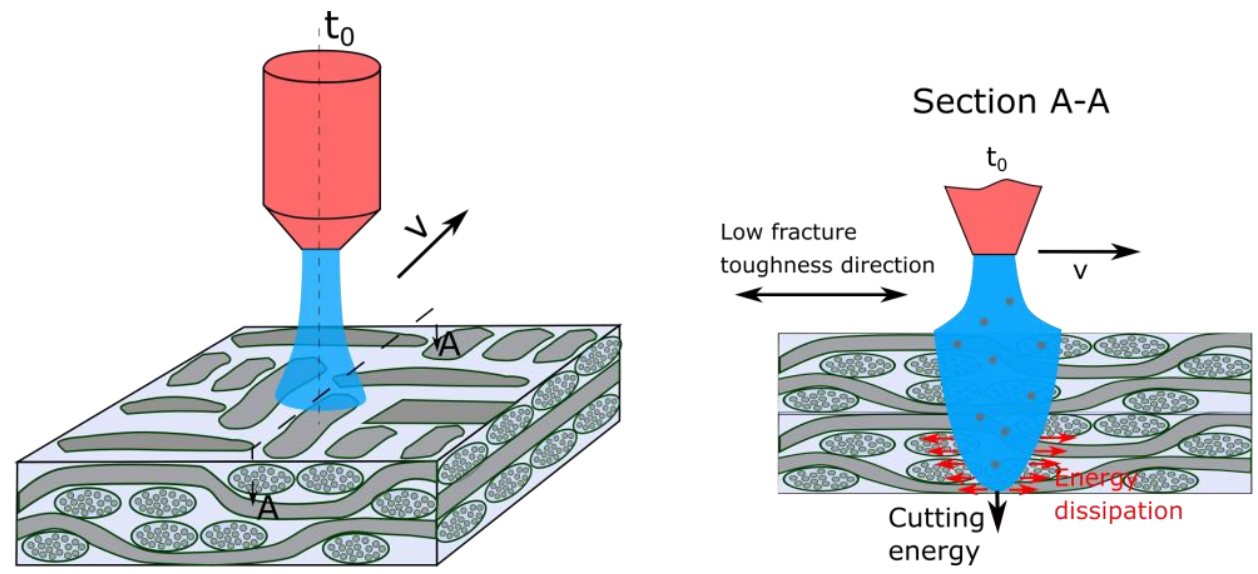

(a)
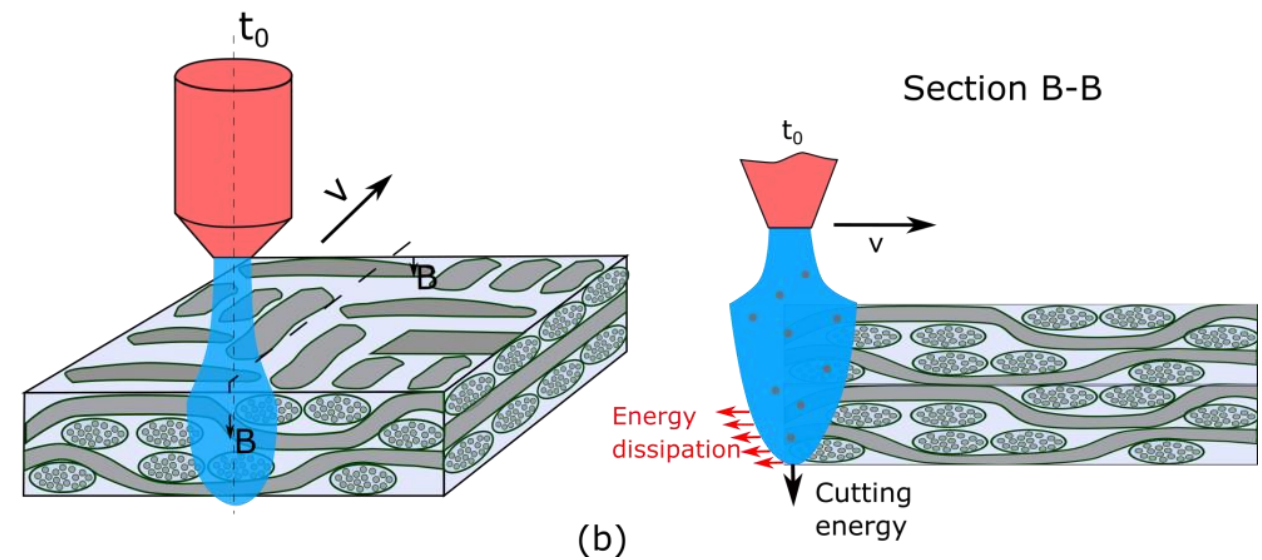

Figure 23 Schematic showing the influence of the AWJ when machining hard CMCS depending whether (a) the jet starts in the middle of the workpiece or (b) at the edge.

Nevertheless, it was shown by Hashish et al. [77] that AW] can be a suitable and efficient technique to machined holes, slots and through cuts in $\mathrm{SiC} / \mathrm{SiC}$ and $\mathrm{Al}_{2} \mathrm{O}_{3} / \mathrm{Al}_{2} \mathrm{O}_{3} \mathrm{CMCs}$ if the operating parameters (especially the starting conditions such as pressure and rate of abrasives) are optimised. On the other hand, process related defects can still be originated 
due to the complex nature of CMCs. The main process-related defects reported were chipping, rounding, tapering, or exit delamination, as shown in Figure 24.

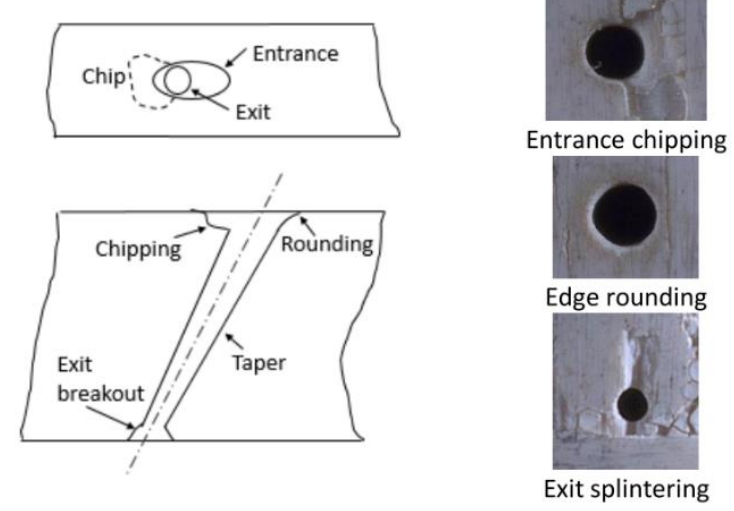

Figure 24 Examples of the main defects normally found in orthotropic brittle materials such as CMCs [77].

Finally, when machining a $\mathrm{SiC} / \mathrm{SiC}$, through cuts were successfully achieved leaving however damage evidence such as tapering (see Figure 25a) and chipping of the edges (see Figure 25b). Furthermore, small diameter holes (1-2 mm) were successfully machined in $\approx 6 \mathrm{~mm}$ thick samples, as shown in Figure $25 \mathrm{c}$.
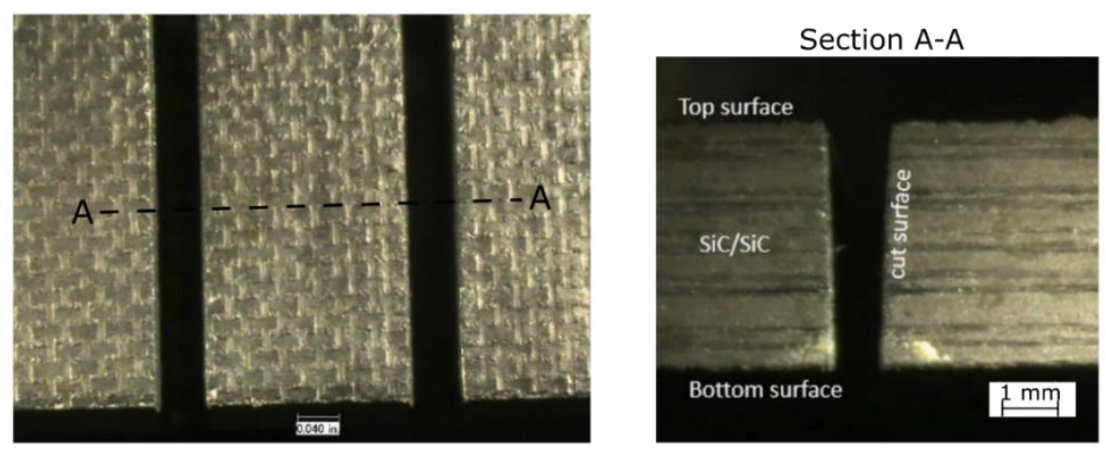

(a)

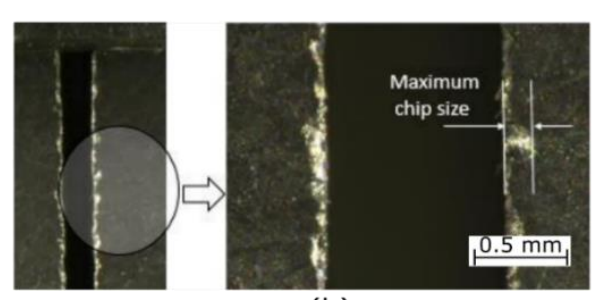

(b)

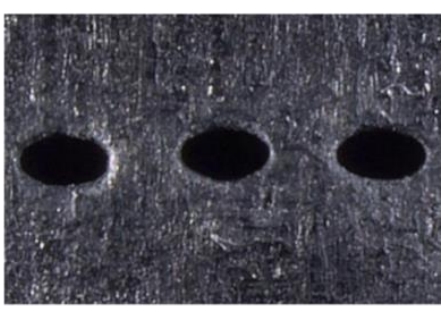

(c)

Figure 25 Examples of (a) through cut, (b) edge fracture and (b) hole making with AWJ in a SiC/SiC material [77].

Hence, it can be concluded that AWJ is a promising technology to machine CMCs and especially, to perform fast through cuts. Furthermore, if the parameters are carefully chosen, small features such as holes can also be successfully achieved. On the other hand, a further in-depth study characterising the surface integrity AWJ of CMCs, is highly needed before being able to compare it to other more established and reported technologies such as laser or conventional machining. 


\subsection{Electrical Discharge machining (EDM)}

Electrical discharge machining is a technique widely employed to perform cuts and holes in electrically conductive materials which are difficult-to-cut by conventional methods. However, a huge instantaneous temperature is built up due to the process' sparks, affecting the machined surface not only due to the temperature damage but also due to the difference between temperature properties among the components (i.e. the different CTE between the fibres and the matrix could lead to residual stress levels). Some review works treating the EDM of ceramics mainly focuses on the prediction of the process forces [78], [79] and little investigation was made on ceramic composites while CMCs are barely mentioned.

The ED hole-making operation on $\mathrm{C} / \mathrm{C}$ composites was experimentally investigated determining that pulse current, gap voltage and pulse on time are, respectively, the most influencing parameters on the process in terms of hole circularity and overcut [80]. Other investigations [81], [82] showed the possibility of preventing fibre breakage and delamination (always greater at the entry surface than at the exit) at low pulse current (lower than $0.2 \mathrm{~A}$ ). The main material removal mechanisms dominating the process were defined as melting and evaporation, leading to a more severe damage along longitudinal fibres [81]. EDX analysis on the recast layer revealed the existence of Copper from the electrode when increasing the peak current, which once deposited on the machined surface arrested the crack propagation along the fibre direction [82]. Wei et al. [83] conducted a comparative investigation on the performance of different EDM techniques: conventional EDM against EDM with electrode vibration and with deep flushing were tested in a SiC/SiC sample. It was verified that an efficient debris evacuation was critical to avoid excessive damage on the workpiece and consequently, both tool vibration and deep flushing improved the surface quality. The matrix was eliminated through cracking onset and propagation (along the fibre direction), leading to stripping-off from the unmachined material. Exposed fibres were then broken in a brittle manner due to thermal expansion and compression produced by the sparks, as shown in Figure 26. Nevertheless, further studies concerning surface integrity and the industrial have not yet been studied.

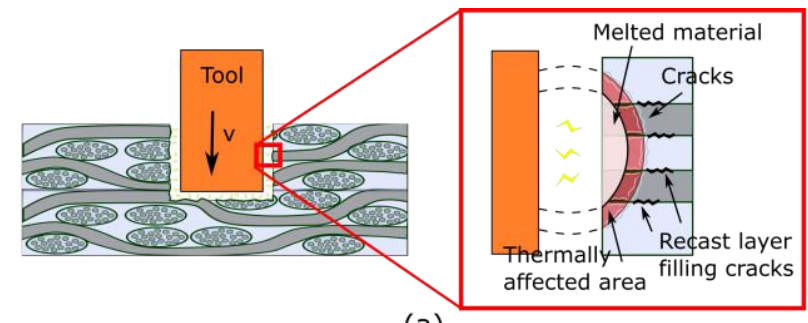

(a)

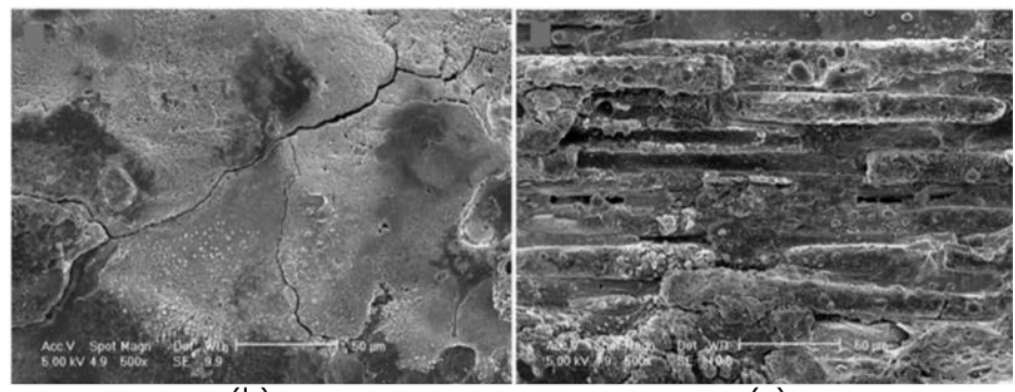

(b)

(c)

Figure 26 (a) Schematic showing the damage in CMCs when machining with EDM and damages on the EDM surface: (b) growing and expansion of thermal cracks [83], (c) fibre exposure and breakage after chipping of the matrix [83]. 
Therefore, after this detailed literature review covering the conventional and nonconventional machining techniques tested in CMCs, it can be concluded that there is not an evident technique which provides a "damage-free" machined surface when removal material in this group an ultra-hard composite structures.

\section{Conclusions}

The recent growth in demand of CMC materials in the aerospace, nuclear and automotive industries has resulted the need of developing an understanding of the machining processes. However, due to the unique nature that these materials present (i.e. hard, brittle, heterogeneous and orthotropic) they are considered very difficult-to-machine and hence several conventional and non-conventional machining processes have been attempted in the literature.

Based on a mapping of the existing published literature, it can be observed (Figure 27) that, on the one hand, the amount of research publications (mainly in China), in the field of machining CMCs has considerably grown during the last five years, particularly for mechanical/conventional and laser machining processes. On the other hand, although very promising machining techniques, the research on abrasive waterjet and electrical discharge machining has been considerably less studied. Furthermore, it can be observed that the $\mathrm{CMC}$ attracting more interest for the machining research is the $\mathrm{C} / \mathrm{SiC}$ followed by the $\mathrm{SiC} / \mathrm{SiC}$.

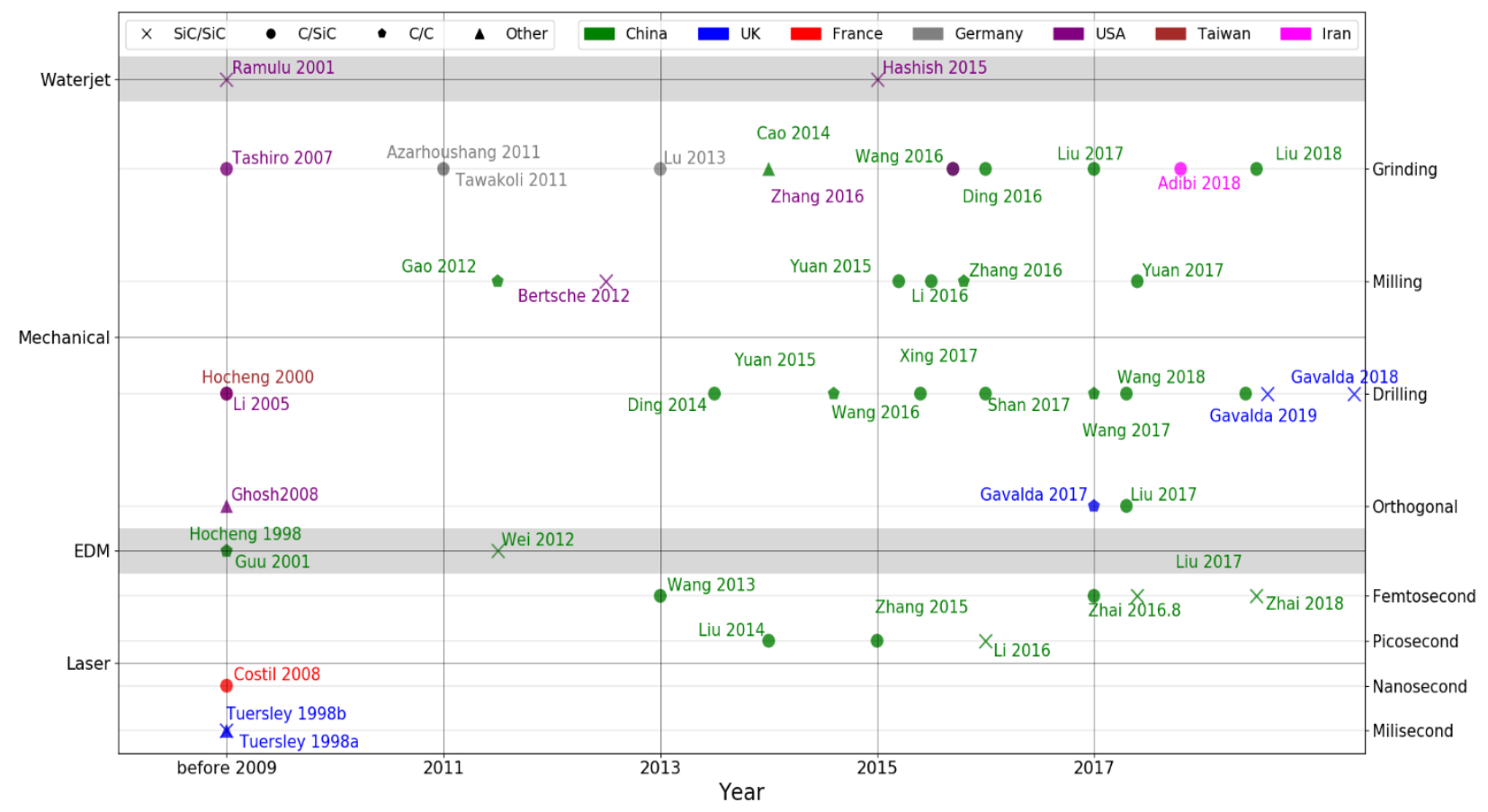

Figure 27 Overview over the last 10 years with the different conventional and nonconventional machining process studied in CMCs, classified by CMC type and country.

Thus, based on the in-depth review on conventional and non-conventional machining techniques, it can be concluded that so far, there is not an exclusive method for which CMCs can be successfully machined achieving all the final features (i.e. hole-making, slotting, surface finishing) needed in the industries. However, from the most relevant results obtained the following conclusions can be drawn: 
- In mechanical machining (e.g. drilling, milling and grinding) the different material removal mechanisms appearing when cutting orthotropic-brittle materials highly affect the surface by inducing different fracture evidence and a combination between ductile and brittle behaviours (based on the uncut chip thickness used). The surface integrity has been mainly evaluated by understanding the fracture and microstructural changes via electron microscopy (i.e. SEM and TEM). Furthermore, relevant results on residual stresses for the different components of the CMC structure were reported via Raman Spectroscopy and could be one of the quantitative methods needed to compare the performance of different machining processes/tools.

- In PLA, an in-depth understanding of the surface degradation caused by the process-induced temperature is proposed for different laser technologies (i.e. nanosecond, picosecond and femtosecond) via SEM, X-Ray CT, XPS and EDS. It is widely concluded that, the formation of an oxide layer in the machined surface is difficult to avoid when machining holes, but it can be highly improved by using ultrafast pulse technologies (e.g. femtosecond ablation) and by optimising the laser power. Moreover, it could also be commented that the machining time needed to achieve good surfaces is long and therefore, it might be only industrially viable when removing little amount of material.

- The literature available in AWJ machining of CMCs reported a feasibility study on machining through cuts and holes in $\mathrm{SiC} / \mathrm{SiC}$ and $\mathrm{Al}_{2} \mathrm{O}_{3} / \mathrm{Al}_{2} \mathrm{O}_{3}$ materials. It is known that, especially for cuts started within the samples, the laminated structure (i.e. orthotropic nature) of CMCs might tend to delaminate when starting the water jet within the sample and hence precautions (e.g. ramping of pump pressure) in the setup might need to be first studied. Little information about the surface integrity is reported in these studies and hence the authors encourage the community to further investigate this field.

- Little literature is available for the EDM of CMCs. This could be caused by the limited electrical conductivity of some of the constituents of several CMCs and the tendency to create local thermal damages due to the anisotropic thermal distribution. Moreover, tool wear due to the localised build-up current might also a limiting factor when using ED-based processes.

Hence, it can be concluded that depending on the operation, different machining techniques might need to be used and consequently different material characterisation methods. Table 1 lists, for each of the machining processes, its relative feasibility to machine holes, slots, off-cuts or smooth the surface.

Table 1 Feature/Operation which could be successfully applied in CMCs based on the machining process.

\begin{tabular}{|c|c|c|c|c|}
\hline \multirow[b]{2}{*}{ Machining process } & \multicolumn{4}{|c|}{ Feature/Operation } \\
\hline & Hole & Slot & Off-cut & $\begin{array}{c}\text { Surface } \\
\text { Smoothing }\end{array}$ \\
\hline $\begin{array}{c}\text { Conventional } \\
\text { (Drilling, Milling and } \\
\text { Grinding) }\end{array}$ & $\begin{array}{c}\stackrel{+}{(\text { drilling holes }} \\
\varnothing>1 \mathrm{~mm})\end{array}$ & $\begin{array}{c}+ \\
\text { (milling or } \\
\text { grinding) }\end{array}$ & $\begin{array}{c}\mathbf{0} \\
\text { (time consuming) }\end{array}$ & $\underset{\text { (grinding) }}{+}$ \\
\hline $\begin{array}{l}\text { Pulsed Laser Ablation } \\
\text { (PLA) }\end{array}$ & $\begin{array}{c}\underset{(\text { holes } \varnothing<1 \mathrm{~mm})}{+} \\
-\end{array}$ & $\underset{\text { (small features) }}{+}$ & $\begin{array}{c}- \\
\text { (time consuming) }\end{array}$ & $\underset{\text { (small regions) }}{+}$ \\
\hline
\end{tabular}




\begin{tabular}{|c|c|c|c|c|}
\hline $\begin{array}{c}\text { Abrasive Waterjet } \\
\text { (AWJ) }\end{array}$ & $\begin{array}{c}+ \\
\text { (More literature } \\
\text { needed) }\end{array}$ & $\begin{array}{c}\mathbf{0} \\
\text { (More literature } \\
\text { needed) }\end{array}$ & $\begin{array}{c}+ \\
\text { (Relatively fast) }\end{array}$ & $\begin{array}{c}- \\
\text { (More literature } \\
\text { needed) }\end{array}$ \\
\hline $\begin{array}{c}\text { Electrical Discharge } \\
\text { Machining (EDM) }\end{array}$ & $\begin{array}{c}\mathbf{0} \\
\text { (More literature } \\
\text { needed) }\end{array}$ & $\begin{array}{c}\mathbf{0} \\
\text { (More literature } \\
\text { needed) }\end{array}$ & $\begin{array}{c}\mathbf{0} \\
\text { (More literature } \\
\text { needed) }\end{array}$ & $\begin{array}{c}\mathbf{0} \\
\text { (More literature } \\
\text { needed) }\end{array}$ \\
\hline \multicolumn{2}{|r|}{$(+)$ recommended, $(0)=$ not enough information, $(-)=$ not recommended } \\
\hline
\end{tabular}

\section{Prospective outlook}

The authors believe that it would be of great interest for the scientific and industrial communities to further develop initial research done in the field of fundamentals of material removal mechanisms by developing analytical or numerical models to understand the cutting mechanics. Moreover, as done for other high temperature and performance alloys, a study of how different material removal processes affect the mechanical performance of the material (i.e. fatigue, creep, degradation) would be highly relevant for the aerospace and nuclear industry. This should be very valuable information to take into consideration when selecting which machining process to use in CMCs.

Furthermore, it is important to emphasise that the study of potential characterisation techniques suitable and needed to understand the surface integrity in CMCs is still in a premature stage. For example, compared to other metallic materials, it has not been yet quantified how the damage (e.g. residual stresses, cracks or oxidised layers) progresses in depth depending on the process parameters, cutting tools or nature of the CMC (e.g. interphases). Hence, the authors believe that the machining community could work with material scientists to study more in-depth the causes of surface damages after machining by establishing more generic characterisation rules. 


\section{References}

[1] A. K. Kaw, Mechanics of composite materials. CRC Press, 1997.

[2] R. Teti, "Machining of Composite Materials," CIRP Ann. - Manuf. Technol., vol. 51, no. 2, pp. 611-634, 2002.

[3] D. Liu, Y. Tang, and W. L. Cong, "A review of mechanical drilling for composite laminates," Compos. Struct., vol. 94, no. 4, pp. 1265-1279, 2012.

[4] C. Dandekar, Y. S.-I. J. of M. tools and, and undefined 2012, "Modeling of machining of composite materials: A review," Elsevier.

[5] M. S. Rayat, S. S. Gill, R. Singh, and L. Sharma, "Fabrication and machining of ceramic composites - A review on current scenario," Mater. Manuf. Process., vol. 32, no. 13, pp. 1451-1474, 2017.

[6] J. Di Carlo, "Advances in SiC/SiC composites for aero-propulsion," in Ceramic Matrix Composites: Materials, Modelling and Technology, Hobooken, NJ, USA: John Wiley \& Sons, Inc., 2014, pp. 217-235.

[7] W. Krenkel and J. Georges Thébault, "Ceramic Matrix Composites for Friction Applications," in Ceramic Matrix Composites, Hoboken, NJ, USA: John Wiley \& Sons, Inc., 2014, pp. 647-671.

[8] C. Sauder, "Ceramic Matrix Composites: Nuclear Applications," in Ceramic Matrix Composites, Hoboken, NJ, USA: John Wiley \& Sons, Inc., 2014, pp. 609-646.

[9] G. M. Intelligence, "CES EDUPACK 2009." Granta Design Limited.

[10] A. G. Evans and F. W. Zok, "The physics and mechanics of fibre-reinforced brittle matrix composites," J. Mater. Sci., vol. 29, no. 15, pp. 3857-3896, 1994.

[11] B. Heidenreich, "C/SiC and C/C-SiC Composites," in Ceramic Matrix Composites, Hoboken, NJ, USA: John Wiley \& Sons, Inc., 2014, pp. 147-216.

[12] P. Spriet, "CMC Applications to Gas Turbines," in Ceramic Matrix Composites, Hoboken, NJ, USA: John Wiley \& Sons, Inc., 2014, pp. 591-608.

[13] H. Hatta, R. Weiss, and P. David, "Carbon/Carbons and their indsutrial applications," in Ceramic Matrix Composites: Materials, Modelling and Technology, Hobooken, NJ, USA: John Wiley \& Sons, Inc., 2014, pp. 87-146.

[14] K. Keller, G. Jefferson, and R. Kerans, "Oxide-Oxide Composites," in Ceramic Matrix Composites: Materials, Modelling and Technology, Hobooken, NJ, USA: John Wiley \& Sons, Inc., 2014, pp. 236-272.

[15] Y. Kagawa and S. Guo, "Ultrahigh temperature ceramic-based composites," in Ceramic Matrix Composites: Materials, Modelling and Technology, Hobooken, NJ, USA: John Wiley \& Sons, Inc., 2014, pp. 273-292.

[16] J. Sylvia, "Ultra high Temperature Ceramics UHTCs," 2015.

[17] R. Savino, L. Criscuolo, G. D. Di Martino, and S. Mungiguerra, "Aero-thermochemical characterization of ultra-high-temperature ceramics for aerospace applications," J. Eur. Ceram. Soc., vol. 38, no. 8, pp. 2937-2953, 2018.

[18] R. R. Naslain, "SiC-Matrix Composites: Tough Ceramics for Thermostructural Application in Different Fields," Eng. Ceram. Curr. Status Futur. Prospect., vol. 84, pp. 142-159, 2016.

[19] D. B. Marshall and J. B. Davis, "Ceramics for future power generation technology: fiber reinforced oxide composites," Curr. Opin. Solid State Mater. Sci., vol. 5, pp. 
283-289, 2001.

[20] P. Jannotti, G. Subhash, J. Zheng, and V. Halls, "Measurement of microscale residual stresses in multi-phase ceramic composites using Raman spectroscopy," Acta Mater., vol. 129, pp. 482-491, 2017.

[21] B. L. Wing and J. W. Halloran, "Microstress in the Matrix of a Melt-Infiltrated $\mathrm{SiC} / \mathrm{SiC}$ Ceramic Matrix Composite," J. Am. Ceram. Soc., vol. 38, no. 1, pp. 4249, 2017.

[22] A. Ayrikyan et al., "Investigation of residual stress in lead-free BNT-based ceramic/ceramic composites," Acta Mater., 2018.

[23] B. J. F. Kahles and M. Field, "Paper 4: SURFACE INTEGRITY-A NEW REQUIREMENT FOR SURFACES GENERATED BY MATERIAL-REMOVAL METHODS," in Proceedings of the Institution of Mechanical Engineers, Conference Proceedings, 1967, pp. 3145.

[24] A. Thakur and S. Gangopadhyay, "State-of-the-art in surface integrity in machining of nickel-based super alloys," Int. J. Mach. Tools Manuf., vol. 100, pp. 25-54, 2016.

[25] E. J. Opila and N. S. Jacobson, "Corrosion of Ceramic Materials." NASA, 1999.

[26] G. N. Morscher, "Stress-environmental effects on fiber-reinforced SiC-based composites," in Ceramic Matrix Composites: Materials, Modelling and Technology, Bansal and., Wiley, 2010.

[27] O. Gavalda Diaz and D. Axinte, "Towards understanding the cutting and fracture mechanism in ceramic matrix composites," Int. J. Mach. Tools Manuf., vol. 118119, no. March, pp. 12-25, 2017.

[28] Q. Liu, G. Huang, X. Xu, C. Fang, and C. Cui, "Influence of grinding fiber angles on grinding of the 2D C/ C - SiC composites," Ceram. Int., no. February, pp. 0-1, 2018.

[29] D. Ghosh, G. Subhash, R. Radhakrishnan, and T. S. Sudarshan, "Scratch-induced microplasticity and microcracking in zirconium diboride-silicon carbide composite," Acta Mater., vol. 56, no. 13, pp. 3011-3022, 2008.

[30] D. Ghosh, G. Subhash, and G. R. Bourne, "Inelastic deformation under indentation and scratch loads in a ZrB2-SiC composite," J. Eur. Ceram. Soc., vol. 29, no. 14, pp. 3053-3061, 2009.

[31] D. Ghosh, G. Subhash, and N. Orlovskaya, "Measurement of scratch-induced residual stress within $\mathrm{SiC}$ grains in ZrB2-SiC composite using micro-Raman spectroscopy," Acta Mater., vol. 56, no. 18, pp. 5345-5354, 2008.

[32] J. Wang, P. Feng, J. Zheng, and J. Zhang, "Improving hole exit quality in rotary ultrasonic machining of ceramic matrix composites using a compound step-taper drill," Ceram. Int., vol. 42, no. 12, pp. 13387-13394, 2016.

[33] Y. Xing, J. Deng, G. Zhang, Z. Wu, and F. Wu, "Assessment in drilling of C/C-SiC composites using brazed diamond drills," J. Manuf. Process., vol. 26, pp. 31-43, 2017.

[34] K. Ding, Y. Fu, H. Su, Y. Chen, X. Yu, and G. Ding, "Experimental studies on drilling tool load and machining quality of $\mathrm{C} / \mathrm{SiC}$ composites in rotary ultrasonic machining," J. Mater. Process. Tech., vol. 214, no. 12, pp. 2900-2907, 2014.

[35] P. Feng, J. Wang, J. Zhang, and J. Zheng, "Drilling induced tearing defects in rotary ultrasonic machining of $\mathrm{C} / \mathrm{SiC}$ composites," Ceram. Int., vol. 43 , no. 1 , pp. 
791-799, 2017.

[36] H. Hocheng, N. H. Tai, and C. S. Liu, "Assessment of ultrasonic drilling of C / SiC composite material," Mater. Sci., vol. 31, pp. 133-142, 2000.

[37] Z. C. Li, Y. Jiao, T. W. Deines, Z. J. Pei, and C. Treadwell, "Rotary ultrasonic machining of ceramic matrix composites: Feasibility study and designed experiments," Int. J. Mach. Tools Manuf., vol. 45, no. 12-13, pp. 1402-1411, 2005.

[38] J. Wang, J. Zhang, and P. Feng, "Effects of tool vibration on fiber fracture in rotary ultrasonic machining of $\mathrm{C} / \mathrm{SiC}$ ceramic matrix composites," Compos. Part B Eng., vol. 129, pp. 233-242, 2017.

[39] O. Gavalda Diaz, D. Axinte, P. Butler-Smith, and D. Novovic, "On understanding the microstructure of SiC/SiC Ceramic Matrix Composites (CMCs) after a material removal process," Mater. Sci. Eng. A, vol. 713, no. 26, 2018.

[40] O. G. Diaz, D. A. Axinte, and D. Novovic, "Probabilistic modelling of tool unbalance during cutting of hard- heterogeneous materials: A case study in Ceramic Matrix Composites (CMCs )," Compos. Part B, vol. 148, no. March, pp. 217-226, 2018.

[41] C. Zhang, S. Yuan, M. Amin, H. Fan, and Q. Liu, "Development of a cutting force prediction model based on brittle fracture for $\mathrm{C} / \mathrm{SiC}$ in rotary ultrasonic facing milling," Int. J. Adv. Manuf. Technol., vol. 85, no. 1-4, pp. 573-583, 2016.

[42] S. Yuan, H. Fan, M. Amin, C. Zhang, and M. Guo, "A cutting force prediction dynamic model for side milling of ceramic matrix composites C / SiC based on rotary ultrasonic machining," Int. J. Adv. Manuf. Technol., pp. 37-48, 2016.

[43] Z. Li, S. Yuan, and C. Zhang, "Research on the Rotary Ultrasonic Facing Milling of Ceramic Matrix Composites," Procedia CIRP, vol. 56, pp. 428-433, 2016.

[44] S. Yuan, Z. Li, C. Zhang, and A. Guskov, "Research into the transition of material removal mechanism for $\mathrm{C} / \mathrm{SiC}$ in rotary ultrasonic face machining," Int. J. Adv. Manuf. Technol., 2017.

[45] G. F. Gao, Y. Y. Zhao, and X. H. Ma, "Research on Tool Wear and Surface Characteristics in Ultrasonic Milling Carbon Fibre Reinforced Carbon Composite," Adv. Mater. Res., vol. 497, pp. 299-303, 2012.

[46] E. Bertsche, K. Ehmann, and K. Malukhin, "Ultrasonic slot machining of a silicon carbide matrix composite," Int. J. Adv. Manuf. Technol., vol. 66, no. 5-8, pp. 1119-1134, 2013.

[47] X. Dong and Y. C. Shin, "Improved machinability of $\mathrm{SiC} / \mathrm{SiC}$ ceramic matrix composite via laser-assisted micromachining," Int. J. Adv. Manuf. Technol., vol. 90, no. 1-4, pp. 731-739, 2017.

[48] J. C. Rozzi and M. D. Barton, "The laser-assisted edge milling of ceramic matrix composites," in ASME 2009 International Manufacturing Science and Engineering Conference, 2016, pp. 1-8.

[49] L. Zhang, C. Ren, C. Ji, Z. Wang, and G. Chen, "Effect of fiber orientations on surface grinding process of unidirectional C/SiC composites," Appl. Surf. Sci., vol. 366, pp. 424-431, 2016.

[50] Q. Liu, G. Huang, X. Xu, C. Fang, and C. Cui, "A study on the surface grinding of 2D C/SiC composites," Int. J. Adv. Manuf. Technol., pp. 1-9, 2017.

[51] J. Du et al., "New observations of the fiber orientations effect on machinability in grinding of $\mathrm{C} / \mathrm{SiC}$ ceramic matrix composite," Ceram. Int., vol. 44, no. May, pp. 
13916-13928, 2018.

[52] S. Otani and A. Ōya, "Progress of pitch-based carbon fiber in Japan," Am. Chem. Soc., 1986.

[53] E. Frank, L. M. Steudle, D. Ingildeev, J. M. Spörl, and M. R. Buchmeiser, "Carbon fibers: Precursor systems, processing, structure, and properties," Angew. Chemie - Int. Ed., vol. 53, no. 21, pp. 5262-5298, 2014.

[54] X. Cao, B. Lin, Y. Wang, and S. Wang, "Influence of diamond wheel grinding process on surface micro-topography and properties of SiO2/SiO2 composite," Appl. Surf. Sci., vol. 292, pp. 181-189, 2014.

[55] X. Cao, B. Lin, and X. Zhang, "A study on grinding surface waviness of woven ceramic matrix composites," Appl. Surf. Sci., vol. 270, pp. 503-512, 2013.

[56] X. Cao, B. Lin, and X. Zhang, "Investigations on grinding process of woven ceramic matrix composite based on reinforced fiber orientations," Compos. Part $B$ Eng., vol. 71, pp. 184-192, 2015.

[57] T. Tawakoli and B. Azarhoushang, "Intermittent grinding of ceramic matrix composites (CMCs) utilizing a developed segmented wheel," Int. J. Mach. Tools Manuf., vol. 51, no. 2, pp. 112-119, 2011.

[58] B. Azarhoushang, "Wear of non-segmented and segmented diamond wheels in high-speed deep grinding of carbon fibre-reinforced ceramics," Int. J. Adv. Manuf. Technol., vol. 74, no. 9-12, pp. 1293-1302, 2014.

[59] B. Azarhoushang and T. Tawakoli, "Development of a novel ultrasonic unit for grinding of ceramic matrix composites," Int. J. Adv. Manuf. Technol., vol. 57, no. 9-12, pp. 945-955, 2011.

[60] K. Ding, Y. Fu, H. Su, F. Cui, Q. Li, and W. Lei, "Study on surface / subsurface breakage in ultrasonic assisted grinding of $\mathrm{C} / \mathrm{SiC}$ composites," Int. J. Adv. Manuf. Technol., pp. 3095-3105, 2017.

[61] K. Ding, Y. Fu, H. Su, Y. Chen, X. Yu, and G. Ding, "Experimental studies on drilling tool load and machining quality of $\mathrm{C} / \mathrm{SiC}$ composites in rotary ultrasonic machining," J. Mater. Process. Technol., vol. 214, no. 12, pp. 2900-2907, 2014.

[62] W. Li et al., "Effect of different parameters on machining of SiC/SiC composites via pico-second laser," Appl. Surf. Sci., vol. 364, pp. 378-387, 2016.

[63] I. . R. P. I . P. Tuersley, T. P. Hoult, "The processing of SiC - SiC ceramic matrix composites using a pulsed Nd-YAG laser Part II The effect of process variables," $J$. Mater. Sci., vol. 3, pp. 963-967, 1998.

[64] S. Costil, S. Lukat, C. Langlade, and C. Coddet, "Surface modification of ceramic matrix composites induced by laser treatment," Appl. Surf. Sci., vol. 255, no. 5 PART 1, pp. 2425-2432, 2008.

[65] Y. Liu et al., "Effect of energy density and feeding speed on micro-hole drilling in C/SiC composites by picosecond laser," J. Mater. Process. Technol., vol. 214, no. 12, pp. 3131-3140, 2014.

[66] R. Zhang et al., "Machining parameter optimization of $\mathrm{C} / \mathrm{SiC}$ composites using high power picosecond laser," Appl. Surf. Sci., vol. 330, pp. 321-331, 2015.

[67] C. Wang, L. Zhang, Y. Liu, G. Cheng, Q. Zhang, and K. Hua, "Ultra-short pulse laser deep drilling of C/SiC composites in air," Appl. Phys. A Mater. Sci. Process., vol. 111, no. 4, pp. 1213-1219, 2013.

[68] Z. Zhai et al., "Influence of surface morphology on processing of C/SiC composites 
via femtosecond laser," Compos. Part A Appl. Sci. Manuf., vol. 102, pp. 117-125, 2017.

[69] Y. Liu et al., "Effect of machining parameter on femtosecond laser drilling processing on SiC/SiC composites," Int. J. Adv. Manuf. Technol., pp. 1-17, 2017.

[70] Z. Zhai, W. Wang, X. Mei, M. Li, and J. Cui, "Effect of the surface microstructure ablated by femtosecond laser on the bonding strength of EBCs for SiC / SiC composites," Opt. Commun., vol. 424, no. March, pp. 137-144, 2018.

[71] P. Rudolph, K. W. Brzezinka, R. Wäsche, and W. Kautek, "Physical chemistry of the femtosecond and nanosecond laser-material interaction with $\mathrm{SiC}$ and a SiCTiC-TiB2composite ceramic compound," Appl. Surf. Sci., vol. 208-209, no. 1, pp. 285-291, 2003.

[72] D. S. Srinivasu and D. A. Axinte, "Mask-Less Pocket Milling of Composites by Abrasive Waterjets: An Experimental Investigation," J. Manuf. Sci. Eng., vol. 136, no. 4, p. 041005, 2014.

[73] D. K. Shanmugam and S. H. Masood, "An investigation on kerf characteristics in abrasive waterjet cutting of layered composites," J. Mater. Process. Technol., vol. 209, no. 8, pp. 3887-3893, 2009.

[74] D. S. Srinivasu, D. A. Axinte, P. H. Shipway, and J. Folkes, "Influence of kinematic operating parameters on kerf geometry in abrasive waterjet machining of silicon carbide ceramics," Int. J. Mach. Tools Manuf., vol. 49, no. 14, pp. 1077-1088, 2009.

[75] G. Hamatani and M. Ramulu, "Machinability of High Temperature Composites by Abrasive Waterjet," Trans. ASME, vol. 112, no. October, pp. 381-386, 1990.

[76] M. Ramulu, G. Jenkins, M, and Z. Guo, "Abrasive Water Jet Machining Mechanisms in Continuous-Fiber Ceramic Composites," J. Compos. Technol. Res., vol. 23, no. 3, pp. 82-91, 2001.

[77] M. Hashish, A. Kotchon, and M. Ramulu, "Status of AWJ machining of CMCS and hard materials," INTERTECH 2015 - An Int. Tech. Conf. Diamond, Cubic Boron Nitride their Appl., no. August, 2015.

[78] M. N. Farooqui and N. G. Patil, "A perspective on shaping of advanced ceramics by electro discharge machining," Procedia Manuf., vol. 20, pp. 65-72, 2018.

[79] Y. Pachaury and P. Tandon, "An overview of electric discharge machining of ceramics and ceramic based composites," J. Manuf. Process., vol. 25, pp. 369390, 2017.

[80] P. M. George, B. K. Raghunath, L. M. Manocha, and A. M. Warrier, "EDM machining of carbon-carbon composite - A Taguchi approach," J. Mater. Process. Technol., vol. 145, no. 1, pp. 66-71, 2004.

[81] Y. H. Guu, H. Hocheng, N. H. Tai, and S. Y. Liu, "Effect of electrical discharge machining on the characteristics of carbon fiber reinforced carbon composites," J. Mater. Sci., vol. 36, no. 8, pp. 2037-2043, 2001.

[82] H. Hocheng, Y. H. Guu, and N. H. Tai, "The feasibility analysis of electricaldischarge machining of carbon-carbon composites," Mater. Manuf. Process., vol. 13, no. 1, pp. 117-132, 1998.

[83] C. Wei, L. Zhao, D. Hu, and J. Ni, "Electrical discharge machining of ceramic matrix composites with ceramic fiber reinforcements," Int. J. Adv. Manuf. Technol., vol. 64, no. 1-4, pp. 187-194, 2013. 
